\title{
"Who'll take the chair?" Maternal employment effects of a Polish (pre)school reform
}

\author{
Yusuf Emre Akgündüz ${ }^{1} \cdot$ Thomas van Huizen $^{2}$ (D) Janneke Plantenga²
}

Received: 19 January 2019 / Accepted: 27 April 2020 / Published online: 8 June 2020

(c) The Author(s) 2020

\begin{abstract}
This study examines the impact of preschool availability on the employment of mothers of preschool-aged children. We exploit a transitional phase of a 2009 Polish education reform that simultaneously lowered the primary school age from 7 to 6 and provided a statutory right to preschool to 5-year-olds. As a significant share of 6-year-old children moved into primary schools a year earlier, their preschool seats effectively became available for younger children. The reform thereby led to a substantial rise in the number of available preschool seats for 3- to 5-year-olds. Using regional variation in the degree of preschool expansion, we estimate the impact of the increased availability of preschool seats on maternal employment. Our results indicate a significant and sizable employment effect: a $10 \%$ points increase in the ratio of preschool seats to preschool-aged children increases maternal employment by around $4.2 \%$ points. The effect seems to be concentrated among highly educated mothers and mothers with a youngest child of age three.
\end{abstract}

Keywords Preschool · Employment $\cdot$ Hours worked $\cdot$ Difference-in-differences

JEL Classification J13 $\cdot$ J21 $\cdot$ J22

\section{Introduction}

While policy makers often point out that the lack of available early childhood education and care (ECEC) is a major impediment to maternal employment, empirical evidence

$凶$ Thomas van Huizen

t.m.vanhuizen@uu.nl

1 Faculty of Arts and Social Sciences, Sabanci University, Orta, Sabanci Unv. No:27, 34956 Tuzla, Istanbul, Turkey

2 Utrecht School of Economics, Utrecht University, Kriekenpitplein 21-22, 3584 EC Utrecht, The Netherlands 
on this issue is rather inconclusive. ${ }^{1}$ A large body of literature has used structural models to estimate the elasticity of female employment with regard to childcare prices and reports elasticities ranging from 0 to 1 (Blau and Currie 2006; Akgündüz and Plantenga 2018). More recently, studies exploiting natural experiments provide evidence that indicates negligible (Cascio and Schanzenbach 2013; Havnes and Mogstad 2011), small (Brilli et al. 2016; Nollenberger and Rodríguez-Planas 2015) or substantial (Bauernschuster and Schlotter 2015) effects of ECEC expansions. These results suggest that the effectiveness of ECEC depends on prevailing maternal employment rates, flexible employment opportunities, other family policies and cultural norms about gender roles.

The central aim of this paper is to contribute to the quasi-experimental literature on the effects of ECEC on maternal employment by evaluating a 2009 (pre)school reform in Poland. The education reform aimed to gradually lower the mandatory primary school age from age 7 to age 6 . The initial years after the reform can be considered as a transitional phase, during which 6-year-olds were not obliged but encouraged to enter primary school. Because at least 1 year of preschool is required before entering primary school, a statutory right to preschool was provided to 5year-olds. The reform differs from other preschool expansions because the number of available preschool places for 3- to 5-year-olds rises as an increasing number of 6year-olds move to primary schools. The preschool seats vacated by 6 -year-olds along with the expansion in facilities had a rapid and substantial effect on the share of 3to 5-year-olds in preschools. Our estimation strategy exploits the reform of 2009 to estimate the effects of increased availability of preschool places on the employment of mothers with children aged between 3 and 5. A control group is particularly important for this period since the reform coincides with a period of economic slowdown.

A difference-in-differences (DD) methodology is employed to estimate the effects using Polish Labour Force Surveys between 2005 and 2011. Statistics Poland provides information on the number of preschool places by regions, which allows us to capture the treatment effect by comparing regions that were affected more with those that were affected less. We further distinguish regional trends from the treatment effect by using mothers of older children as a control group in a difference-in-difference-indifferences (DDD) setup.

Our results show that, as expected, the expansion in preschool places had a strong effect on the enrollment of 3- to 5-year-old children. For every percentage point increase in the number of preschool places available to 3- to 5-year-olds, preschool enrollment of this age group goes up by about 0.5 to $0.6 \%$ points. The results also suggest each preschool seat given up a 6-year-old is taken over by a child aged 3 to 5. Moreover, the preschool expansion had a positive effect on maternal employment both in terms of participation and working hours. The estimated effect sizes appear to be relatively large and are comparable with evidence from Germany (Bauernschuster and Schlotter 2015). For each $10 \%$ point increase in the ratio of preschool places to 3to 5-year-old children, female employment rises by around $4.2 \%$ points. The effects are strongest for highly educated women, indicating that a lack of childcare may be an important barrier to their employment.

\footnotetext{
${ }^{1}$ See Morrissey (2017) for a recent review of the literature.
} 
The study contributes to the growing quasi-experimental literature in several ways. First, the expansion of preschool places for 3- to 5-year-old children in Poland is unique because it is not only caused by an expansion in preschool places but also by the lowering of the compulsory school age. A similar effect may be expected in other countries in case of a reform lowering the compulsory school age since preschool attendance for the year before compulsory school age tends to be very high. Second, quasi-experimental evidence on the maternal employment effects of ECEC in CentralEastern Europe is virtually non-existent. ${ }^{2}$ We believe that Poland is an interesting case as the opportunities for flexible (part-time) work are limited and, as a Catholic country, cultural norms are generally not supportive of employment of mothers with young children (Pignatti 2016). While previous literature suggests that the impact of ECEC on maternal employment will be limited in a country with these characteristics (Lovász 2016), the evidence presented in this study shows the opposite. However, we argue that these substantial effects are likely to be the result of the interaction of several features of the Polish context: virtually no childcare infrastructure for children below the age of three, lengthy post-natal leave (over 3 years) and a reform that has increased the number of seats available for children aged 3 to 5 . Basically, in the post-reform period a larger share of mothers is able to return to work at the end of the parental leave period when the youngest child is aged three. This explanation is consistent with the evidence that the positive employment effect on mothers of 3-year-olds appears to be the main driver of the overall reform effect.

In the next section, we discuss the Polish context and the (pre)school reform and we demonstrate how the reform resulted in a significant expansion in preschool services. Section 3 explains the details of our empirical methodology. Section 4 introduces the data. Section 5 presents the results and robustness tests. Section 6 concludes.

\section{Background}

\subsection{Reconciliation of work and family in Poland}

During communist times, the Polish female employment rate was low compared to other Eastern European states, i.e., the female employment rate was around $64 \%$ in 1988 compared to $89 \%$ in East Germany (Matysiak and Steinmetz 2008). After the fall of communism, the female participation rate fell further to $48 \%$ in 2001 . Since then, the rate increased slowly to $50.8 \%$ in 2008 prior to the reform of interest and further to $53.1 \%$ in 2012 (OECD 2017). Furthermore, fertility rates dropped substantially during the post-socialist era, from around 2.1-2.4 in the 1980s to below 1.3 in the early 2000s (OECD Family Database). Here we discuss several characteristics of the Polish context that are relevant determinants of maternal employment: cultural norms, leave legislation, the childcare infrastructure and the organization of paid employment.

First, an important explanation for the relatively low female employment rate is that the Catholic Church plays an important role in the Polish society and attitudes

\footnotetext{
${ }^{2}$ An exception is the study by Lovász and Szabó-Morvai (2018), who analyze the childcare effect on maternal labor supply exploiting a discontinuity in eligibility in Hungary.
} 
in Poland toward female employment can be characterized as traditional (Heinen and Wator 2006). Such cultural norms may be an important barrier to combine paid employment with child rearing, especially when children are young.

Second, an important area of reconciliation is maternity and parental leave. During the period relevant for our analysis, total post-natal leave is around three and a half years. Mothers are entitled to 20 weeks of maternity leave (18 weeks for a first birth), which is fully paid (Kotowska and Michon 2008). ${ }^{3}$ Furthermore, parents can use parental leave, which is 36 months in total. However, the parental allowance is low (PLN400; $€ 115$ ) and means-tested (per capita household income should not exceed PLN504; €145). Eligible families can receive this allowance for 24 months, but this can be extended to 36 months when more than one child is present. According to the OECD (2015), around 57\% of mothers with a child below the age of one are on paid leave. This relatively low percentage can be explained by the fact that for most women only the first 20 weeks of leave are paid.

Third, there is a general lack of provision of (affordable) childcare and preschool services. The childcare infrastructure for children below the age of 3 is especially underdeveloped. As is common in many European countries, the Polish ECEC services are organized as a split system, distinguishing between facilities for 0- to 2-year-old children and for 3- to 6-year-olds. Children aged 0 to 2 attend crèches and kids' clubs. These services are not part of the education system but are overseen by the Ministry of Labour and Social Policy (until 2011 they were supervised by the Ministry of Health). In general, the supply of childcare services for the youngest children is very limited: "Public authorities justify the limited supply by scarce resources and insufficient demand, whereas the private sector faces barriers to the set-up of new institutions in the form of extensive legal regulations governing the organization of care." (Plomien 2009, p. 139). There are also several factors that explain a low demand for childcare services in the 0-2 age range. As no childcare subsidies are offered to families, childcare services are generally not affordable for lower-income families: the estimated costs range from 23 to $82 \%$ for a worker earning the minimum wage and from 8.5 to $30 \%$ for a worker earning the average wage (Kotowska and Michon 2008). ${ }^{4}$ In addition to the high costs, low demand for these services may also be explained by the rather bad reputation of these services and a persistent belief that children under the age of three should be cared for by the family (e.g., Heinen and Wator 2006). Given that childcare services are often not available nor affordable, the enrolment rate for younger children remains among the lowest in the EU (below 8\% in 2008 according to OECD Family Database). Hence, mothers (re-)entering paid employment have to rely on informal care arrangements. As in many post-socialist countries, grandparents play an important role in the provision of childcare for young children. ${ }^{5}$

\footnotetext{
3 During the post-reform period, maternity leave was extended several times: 20 weeks irrespective of birth order (2009), 2 additional weeks in 2010 and again a further extension of 2 weeks to 26 weeks in total in 2012. Since 2013, an additional 26 weeks with a replacement rate of $60 \%$ was introduced. Parents also had the option to take up 52 weeks with a replacement rate of $80 \%$ (Michon and Kotowska 2013).

4 Plomien (2009) estimates that the costs of childcare in a public centre are around 10-14\% of average income, but 46-79\% in a non-public centre.

5 The share of children in more intensive (i.e., $30 \mathrm{~h}$ per week or more) informal care arrangements is relatively high in Poland. In 2008, among children below the age of 3, $18 \%$ were cared for by grandparents
} 
Preschools for 3- to 6-year-olds are a part of the education system and are therefore supervised by the Ministry of Education. ${ }^{6}$ Children attend either kindergartens (przedszkole) or preschool classes that are attached to or organized by primary schools (oddziaty przedszkolne). Almost all of these arrangements are public. Both types of preschools are open for a minimum of $5 \mathrm{~h}$ a day. However, most kindergartens are open $9 \mathrm{~h}$ a day on all workdays. Public preschools are free for up to $5 \mathrm{~h}$ a day (since 2001); any additional hours are paid according to fees set by local governments. In general, the costs of preschool services for 3- to 6-year-olds are substantially lower than the costs for ECEC for younger children. Given the rather negative attitudes toward childcare services for young children (and high costs), most Poles prefer to start using ECEC services when children are aged 3 and a preschool place is available (Heinen and Wator 2006). Due to differences in provision, parental fees and attitudes, enrolment rates in ECEC for children aged 3-6 are substantially higher than for the younger aged children: in 2008 around $40 \%$ of 3 -year-olds and over $60 \%$ of 5 -yearolds participated in ECEC (see Fig. 1). For children aged 6, ECEC coverage is close to universal as since 2004 children aged 6 are obliged to complete a zero year (Zerowka) in preschool before entering the first grade of primary school (starting at age 7 before the reform). ${ }^{7}$ Given that the entitlement to a place in ECEC starts at age 6 and that the child is less than 3.5-year-old when the total post-natal leave period ends (younger than 6 months when well-paid leave ends), there is a substantial gap between the end of (well-paid) leave and the start of an ECEC entitlement. In general, the provision is insufficient. Due to shortages of places in some municipalities only children aged 6 are offered a place in preschool (Plomien 2009: p. 139).

Next, one of the structural problems is the lack of preschool facilities in rural areas. There have been several initiatives to solve this problem. Since September 2007, there have been other types of preschools established (which are to a large extent funded by the ESF): "preschool centres" and "preschool clubs". However, the enrolment rate in these new forms remains very low (generally not above 2-3\%). Moreover, these services are generally offered for a limited number of hours or days per week and therefore it is unlikely that they play a significant role in facilitating maternal employment (Plomien 2009).

Finally, as in many Eastern European countries, part-time employment is relatively uncommon in Poland. In 2008, around 9\% of mothers with a child in the $0-14$ age range was employed on a part-time basis: this is low compared to several other European countries (e.g., 39\% in Germany), but high compared to most other post-socialist countries (e.g., 2.5\% in Slovak Republic) (OECD Family Database). According to a

\section{Footnote 5 continued}

or other relatives for at least $30 \mathrm{~h}$ per week (vs. the EU average of $10 \%$ ). The share is lower for children between age 3 and the compulsory schooling, but still substantially higher than the EU average (12\% vs. $5 \%$ in 2008) (EU SILC). The use of grandparents as care providers is very common in Poland. According to SHARE data, in Poland more than $40 \%$ of grandparents provide care for their grandchildren (aged ten or younger) on a daily basis (García-Morán and Kuehn 2013).

6 Although generally limited to children aged 3-6, since a 2003 amendment of the School Education Act preschools is allowed to admit children aged 2.5 years. However, this is only under specific circumstances and conditional on the approval of the head of the school or kindergarten (EURYDICE 2010).

7 The aim of the 2004 reform was to improve school readiness: the policy effectively reduced the start of compulsory education from age 7 to age 6 . 
large national survey, only a small fraction (less than two out of ten) women consider the model where the father works full-time and the mother works part-time as the best model to divide paid and unpaid work when children are below the age of 3 . According to around $75 \%$ of women, the best model for families with children in this age range is realized when the father works full-time and the mother (temporarily) leaves the labor market (Michon 2010). In general, part-time work and other forms of flexible work have never played a substantial role in Poland in the reconciliation of work and family life (Plomien 2009; Lovász 2016). This may discourage maternal employment, as it is often challenging to take up full-time employment given the rather rigid hours of ECEC services.

Overall, Polish mothers face several barriers to return to paid employment. Mothers who are in low-wage jobs, have multiple (young) children and do not have access to informal care (by grandparents) are unlikely to return to paid employment in the first years after childbirth. The institutional features discussed above explain why a large share of children below the school age are only cared for by their parents (i.e., they are not in any formal or informal care arrangement). In 2008, 64\% of the Polish children below the age of three were cared for only by their parents (vs. $41 \%$ in the EU). Strikingly, for children between age 3 and the schooling age, this share is about four times the EU average (43\% in Poland and $11 \%$ in the EU) and the share is actually the highest among all EU countries (EU SILC). This suggests that an increase in preschool availability for children aged 3-5 may have significant effects on maternal employment.

\subsection{The Polish (pre)school reform}

The reform that we exploit in this study concerns the simultaneous lowering of the primary school entry age and the introduction of a statutory right to preschool education for 5-year-olds. ${ }^{8}$ In late 2008 , the Polish government decided to lower the compulsory primary school starting age from 7 to 6 and the preschool age from 6 to 5 (see Herbst and Strawiński 2016) for a more extensive discussion on the implementation of the reform). Given that 1 year of preschool is required prior to primary school entry, lowering the preschool age was de facto implied. In the public debate, several (political) reasons were put forward to lower the mandatory school age: (1) the potential cognitive benefits of starting school earlier; (2) an early start in school may replace missing preschool education in rural areas; (3) as a declining student population led to school closures and teacher dismissals, an additional cohort may create extra jobs for teachers; (4) the reform will result in earlier labour market entry of school leavers, increasing the sustainability of the public pension system. Although generally not mentioned as a primary reason for lowering the school entry age, it is likely that this reform may also stimulate maternal employment: "This reform, however, may also improve the ability of parents to reconcile work with family as children would begin their compulsory education a year sooner, thus freeing time and money spent on care and facilitating

\footnotetext{
8 The government intended to further extend the statutory right to a preschool place to younger-aged children and therefore planned to increase the availability of preschool services. In fact, the preschool entitlement was extended to 4-year-olds in 2015 and to 3-year-olds in 2017.
} 
an earlier return to employment for mothers who remained out of work after parental leave." (Plomien 2009: p. 141)

Originally, the education reform of 2009 involved a transition period until 2012 during which parents could choose to enroll their 6-year-old children in either preschools or primary schools, conditional on at least 1 year of prior preschool. To encourage the enrolment of 6-year-olds in primary schools, 5-year-olds were given the statutory right to preschool education as of September 2009. However, a preschool place may in practice not always be available for a 5-year-old: municipalities are responsible for the establishment of sufficient preschool places, but are not always able to do so due to budgetary constraints. Primary school enrolment was meant to be mandatory for 6-year-olds in September 2012 and accordingly preschool enrolment was compulsory for 5-year-olds starting in September 2011. However, from the start the reform faced strong opposition from both parents and teachers. For instance, media campaigns launched by parental organizations (such as "Save the Little Ones") tried to convince parents and other stakeholders that schools were not prepared to provide a safe and stimulating learning environment for large groups of young children. The limited confidence in the reform was also reflected by the relatively low enrolment rate of 6-year-olds in primary school during the transition phase (from $4.3 \%$ in 2009 to $19.4 \%$ in 2011) (Herbst and Strawiński 2016).

In response to the opposition, the government decided in October 2011 to lengthen the transition phase until September 2013. Several months later this was further extended until September 2014. Next, in 2013 the government modified the policy and restricted the mandatory school age for 2014 for children reaching age 6 before July 1 2014. In 2015 the conservative opposition party Law and Justice (PiS), an opponent of reducing the mandatory school age, won the elections and the newly formed government reversed the reform, increasing the mandatory school age to 7 years. While lowering the mandatory school age may have encouraged maternal employment, the policy reversal may generate the opposite effect. This concern has also been raised in an European Commission country report: “. . . the school entry age was recently raised from 6 to 7 years. This change is likely to impact on the availability and take-up of pre-school education, as the 6 years olds will have to stay in kindergartens occupying places that could be allocated to younger children and compulsory pre-school education for 5 years olds will be abolished. These changes are likely to negatively affect children from poorer backgrounds and the supply of labour." (EC 2016, pp. 23-24)

We aim to estimate the impact of the 2009 reform. The main interest of this study is to identify the combined effect of a preschool and school reform on the employment of mothers of preschool-aged children. It can be expected that the reform led to an increase in preschool attendance of 3- to 5-year-olds for two reasons. First, a statutory right to preschool education was provided to 5-year-olds (and there were intentions to extend the entitlement to younger aged groups). Second, as 6-year-olds began moving to primary schools, they left preschool seats vacant for 3- to 5-year olds. The increased availability of preschool seats may also have affected the enrolment of 3- and 4-yearolds, allowing mothers to return to employment earlier and maintain their attachment to the labour market. Given that total post-natal leave is almost 3.5 years, the effects on mothers of 3-year-olds may be pronounced, as increased availability of preschool seats may allow them to return to their employer at the end of the leave period. 


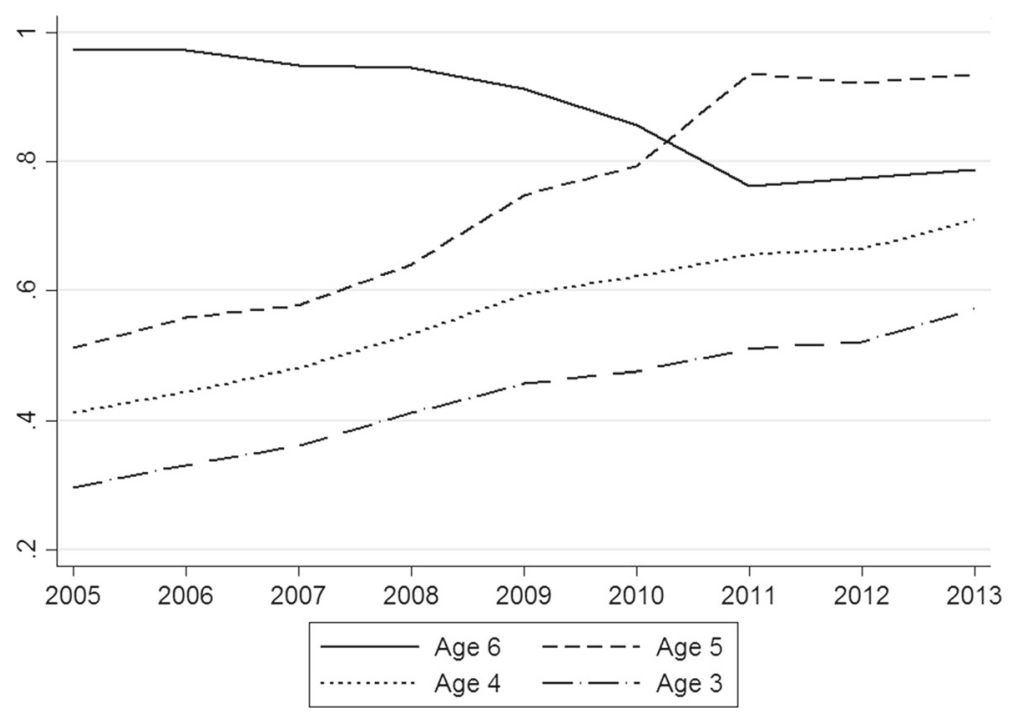

Fig. 1 Preschool attendance rates by age

In the years following the reform, preschool availability and attendance among 3- to 5-year-olds increased substantially. Between 2005 and 2008, the total number of preschool classes increased on average around $2.5 \%$ per year, whereas the total number of preschool classes increased on average around 7.4\% per year in the 20082011 period (Statistics Poland). Moreover, preschool for 6-year-olds was mandatory before the 2009 reform and attendance rates were close to $100 \%$ for this age group; with the 2009 reform, the preschool attendance of 6-year-olds began to decline as they moved into primary school: see Fig. 1. Both developments increased the number of seats available for 3 - to 5-year-olds. Figure 1 shows that preschool participation among 5 -year-olds increased sharply since the reform. Among younger children, preschool enrolment also rises, although less steeply.

We limit our treatment period to 2009-2011 as several other reforms took place in the more recent years. ${ }^{9}$ First, the decision made in October 2011 to lengthen the voluntary phase may have decreased the social confidence of the reform. Second, fees for hours in addition to the free $5 \mathrm{~h}$ per day are capped at 1 PLN (approximately $€ 0.25$ ) since September 2013, affecting the price of preschool services. Third, in addition to these preschool reforms, policy changes in the child care system (for children below the age of 3) and leave legislation may affect outcomes in our treatment and control groups in the more recent years. Specifically, in 2011 the Polish government introduced the nationwide Maluch (Toddler) program to increase the number of childcare places for children below the age of 3 . Moreover, parental leave has been extended gradually in the 2009-2013 period (see Footnote 3): by using 2011 as our last treatment year, we exclude mothers that are affected by this reform (i.e., in 2012, mothers of 3-year-olds were affected by the parental leave reforms). Similarly, in 2011 the Act on Care of

\footnotetext{
${ }_{9}$ However, we tested the robustness of our results by including 2012 and 2013 as treatment years in the analysis (see Sect. 5.2).
} 
Children Aged 3 or Less was passed which formalized the widely used nanny care for children younger than 3. If the 2011 reform led to an ease in finding childcare for children aged 0 to 2 and higher employment for the affected mothers, this should not be reflected among the mothers of 3-year-olds until 2012. Hence, we argue that restricting the treatment period to 2009-2011 limits the issue that we may capture effects of other policy reforms.

\section{Methodology}

\subsection{Estimation strategy}

We use a difference-in-difference-in-differences (DDD) model to isolate the effects of the reform on the employment of mothers of preschool-aged children (i.e., 3- to 5-yearolds). Our first source of variation is the different rates at which preschool availability increased across Polish regions. First, we estimate a difference-in-difference (DD) model to examine the effects of the reform by comparing the outcomes of mothers with the youngest child aged 3-5 between regions with varying degrees of expansion using Eq. (1). We control for year fixed effects, $T_{t}$, area fixed effects $P_{j}$ and personal characteristics such as education, month of the interview and age $X_{i j t}$ in all regressions.

$$
y_{i j t}=a+T_{t}+P_{j}+\gamma X_{i j t}+\beta_{0} R_{i j t}+\beta_{1} R_{i j t} * \text { Post }_{i j t}+e_{i j t}
$$

We define $y_{i j t}$ as the outcome for individual $i$ in province $j$ and year $t$. There are two main outcome variables of interest: employment and working hours. Employment effects are estimated using a linear probability model with the employment variable being 1 if the mother is employed and 0 otherwise. To analyze the effects of the reforms on working hours, we follow Angrist and Pischke (2008) and estimate a linear regression model with the same sample of individuals as in the participation models. $^{10}$

The treatment variable of interest is the interaction of the ratio of preschool places to the number of 3- to 5-year-olds, $R_{i j t}$, and the period after the reform of September 2009, Post $t_{i j t}$. The estimated coefficient $\beta_{1}$ can be interpreted as the effect of an extra place per 3- to 5-year-olds after the reform. As such, the reported effects are intention-to-treat (ITT) effects rather than average treatment effects (ATE). The DD estimates will not be valid if regional expansion of preschool services is correlated with increases in female employment. Beyond the standard arguments that may apply to other studies making use of regional variation in the speed of implementation, the Polish reform is further complicated by the voluntary decision of parents to choose between primary schools and preschools. Since the impact of the reform depends partially on their willingness to send their 6-year-olds to primary schools instead of preschools, this decision will need to be uncorrelated with other unobserved factors that may influence female employment.

\footnotetext{
10 An alternative would have been to use a Heckman selection model (Puhani 2000). However, there is no (credible) exclusion restriction available to effectively identify the selection effect in the first stage.
} 
We can further control for developments in female employment at the regional level by using mothers with older children as a control group and therefore estimating a difference-in-difference-in-differences (DDD) model. Specifically, in our main analyses we use mothers with a youngest child aged 7 or 8 as the control group. ${ }^{11}$ Mothers of 6-year-olds are excluded since their employment may be affected by the switch from preschools to primary schools. As long as regional trends in female employment that are correlated with the expansion of preschools are similar between mothers with a child aged 3 to 5 and aged 7 to 8, the DDD estimate will be unbiased. In the results section, we further test the robustness of the results to the control group choice by defining alternative control groups.

Our main model is the DDD model described in Eq. (2). Compared to the DD specification in Eq. (1), the DDD model introduces the variable $I_{i j t}$, which is a binary variable indicating whether the parent belongs to the treatment (child aged 3-5) or control group (child aged 7-8). We further control for differences between treatment and control groups by including interactions between individual characteristics, regions and treatment group status following Nollenberger and Rodríguez-Planas (2015). The DDD estimate of interest is given by the parameter $\delta$, which is the coefficient of the triple interaction between post-reform, treatment group status and the ratio of preschool places to the number of 3- to 5-year-olds.

$$
\begin{aligned}
y_{i j t}= & a+T_{t}+P_{j}+\gamma X_{i j t}+\beta_{0} R_{i j t}+\beta_{1} R_{i j t} * \text { Post }_{i j t}+ \\
& +\beta_{2} I_{i j t}+\beta_{3} I_{i j t} * \text { Post }_{i j t}+\beta_{4} I_{i j t} * R_{i j t}+\delta I_{i j t} * R_{i j t} * \text { Post }_{i j t}+e_{i j t}
\end{aligned}
$$

A DDD setup using both regional variation and the variation between mothers with different aged children divided into treatment and control groups has previously been used to estimate the effects of child care expansions on maternal employment. In fact, studies have found differing estimates from DDD and DD models (Cascio and Schanzenbach 2013; Nollenberger and Rodríguez-Planas 2015). Estimating the effects using the DD model may not fulfill the common trend assumption for regions with differing child care expansion rates. In the case of Poland, since the timing of the reform coincides with that of the global financial crisis, we may further expect that the impact of the crisis differed across regions. The potential variation in the impact of the crisis may further complicate the identification if it is correlated with the expansion in the preschool places for 3- to 5-year-olds. Overall, a DDD model that compares the change in differences among treatment and control group mothers from regions with varied rates of preschool expansion should be the most preferable approach. Unless the crisis had a different effect on the divergence of employment rates among treatment and control group mothers in different regions and this effect is correlated with the expansion in preschools, the DDD estimate would be unbiased.

\footnotetext{
11 Given the leave and childcare reforms in the post-reform period (see Sect. 2.2), mothers with youngeraged children (age 1-2) are not an appropriate comparison group. However, in Sect. 5.2 we discuss the results using this alternative comparison group.
} 


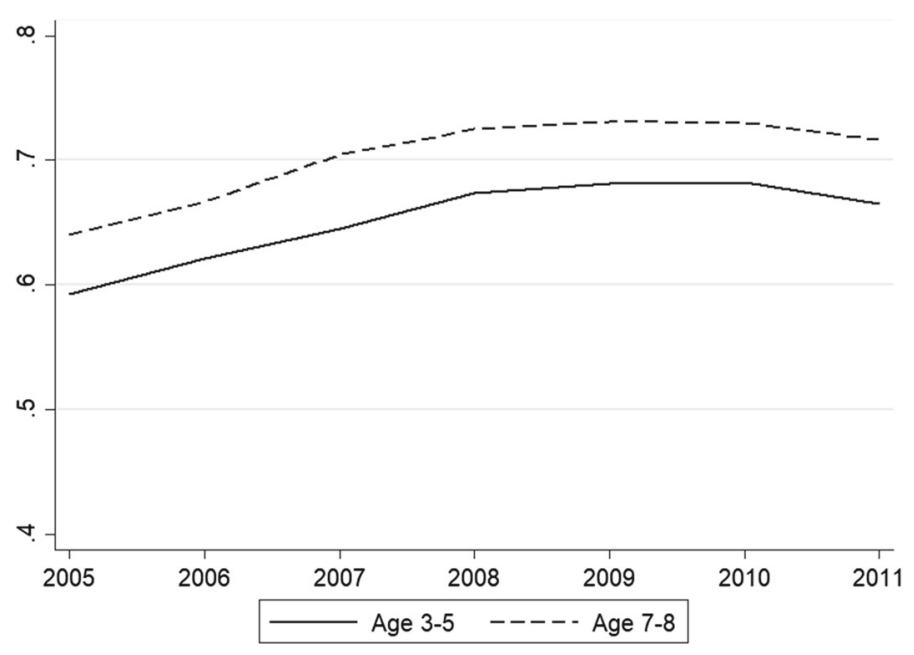

Fig. 2 Average weighted maternal employment rate over time (LFS)

\section{Data}

The primary data source we use in this study is the Polish Labor Force Survey (LFS). LFS is a repeated cross-section survey; each wave is comprised of around 225,000 respondents in 2005 and nearly 420,000 by 2011 . We use survey waves between the years 2005 and 2011 in the analysis. Household characteristics, which are crucial to our analyses, were introduced into the country surveys gradually after 1998. In the Polish LFS, household characteristics are available after 2003. However, as sample sizes are considerably smaller in the waves 2003-2004 (i.e., below 60.000), we do not include these waves in our main analysis. ${ }^{12}$ We limit our samples to mothers who are in the same household as their child and who are aged between 20 and 50.

We use the standard LFS definition and define employment as working at least $1 \mathrm{~h}$ during a week: ${ }^{13}$ Figure 2 presents the development of the employment rate of mothers in the treatment group (youngest child aged 3-5) and in the control group (youngest child aged 7-8). Prior to the financial crisis in 2008, female employment in Poland was rising rather rapidly owing to fast GDP growth (OECD 2008). After 2008, employment growth declined. This seems to be in line with the observation that mothers' entry into the labour market is lower during business cycle downturns (Rønsen and Sundström 1996). Appendix Fig. 6 shows the employment rates by age of the youngest child. The employment rate of mothers with 5-year-olds appears to close the gap with the control group between 2009 and 2011. However, there is a drop in the employment rate of mothers of 3-year-olds in 2010-2011 and a similar decline for the mothers of this cohort in 2011-2012 (i.e., when the children are aged 4) and in 2012-2013 (i.e., when the children are aged 5). The drops in employment seem likely

\footnotetext{
12 We test the impact of including different years as treatment or control years on the results in the placebo tests section.

13 We also tested whether defining employment for mothers working more than $8 \mathrm{~h}$ makes a difference but the results remain largely similar.
} 
Table 1 Summary statistics

\begin{tabular}{llllll}
\hline & Pre-reform & & & Post-reform & \\
& Treatment & Control & & Treatment & Control \\
\hline Polish & 0.9981 & 0.9978 & & 0.9982 & 0.9981 \\
Married & 0.8850 & 0.8756 & & 0.8648 & 0.8543 \\
Age & 32.7899 & 36.1418 & & 33.2187 & 36.4973 \\
Low educated & 0.0973 & 0.1043 & & 0.0774 & 0.0875 \\
Medium educated & 0.6889 & 0.7297 & & 0.6034 & 0.6714 \\
High educated & 0.2138 & 0.1660 & & 0.3192 & 0.2410 \\
Persons in household & 4.5846 & 4.4496 & & 4.4022 & 4.3343 \\
Children aged 6-8 & 0.2781 & 1.0445 & & 0.2441 & 1.0468 \\
Children aged 9-11 & 0.2405 & 0.3274 & & 0.2196 & 0.2957 \\
Children aged 12-14 & 0.1744 & 0.3209 & & 0.1605 & 0.2834 \\
Children aged 15-17 & 0.1229 & 0.2287 & & 0.1089 & 0.2055 \\
$N$ & 21,085 & 12,014 & 18,544 & 9102 \\
\hline
\end{tabular}

to be caused by the timing of birth. Mothers who gave birth during the crisis years of 2008-2009 generally have lower employment rates later on. The DDD estimate should not be affected by the timing of birth and cohort-specific effects since we will be comparing mothers with the same aged youngest child from different regions.

A number of personal characteristics are included in the regressions to control for changes in observable characteristics. The summary statistics of the control variables for both control and treatment groups before and after the reform are presented in Table 1. As expected, mothers in the control group are on average around 3 years older than the treatment group. Furthermore, and related to the age of the mother, the educational level of the treatment group is higher than the control group. The difference in education can be explained by the rapid rise in tertiary education in Poland since 2000 (OECD 2014).

In addition to the Polish LFS, we use data at the regional level acquired from Poland Statistics (2019) to construct a measure of preschool supply. Children can attend one of the two types of preschools: kindergartens or preschool classes attached to primary schools. Statistics Poland provides data on the number of preschool places in kindergartens (the main preschool type in terms of enrolment). Although Statistics Poland does not provide information on the exact number of seats in preschool classes attached to primary schools, data on the number of preschool classes are provided. Since the maximum class size is 25 , we multiply the number of classes with 25 to estimate the number of places in preschool classes attached to primary schools. ${ }^{14}$ We aggregate the number of preschool places in kindergartens and the (estimated) number of places in preschool classes attached to primary schools to calculate the

\footnotetext{
14 We estimated the model with alternative assumptions for class size including 20 and 30 . The larger class size assumptions leads to smaller coefficient estimates while smaller class size assumptions lead to larger coefficient estimates. The direction and significance of the results remain similar since the relevant source of the variation comes from the number of classes rather than the class size.
} 


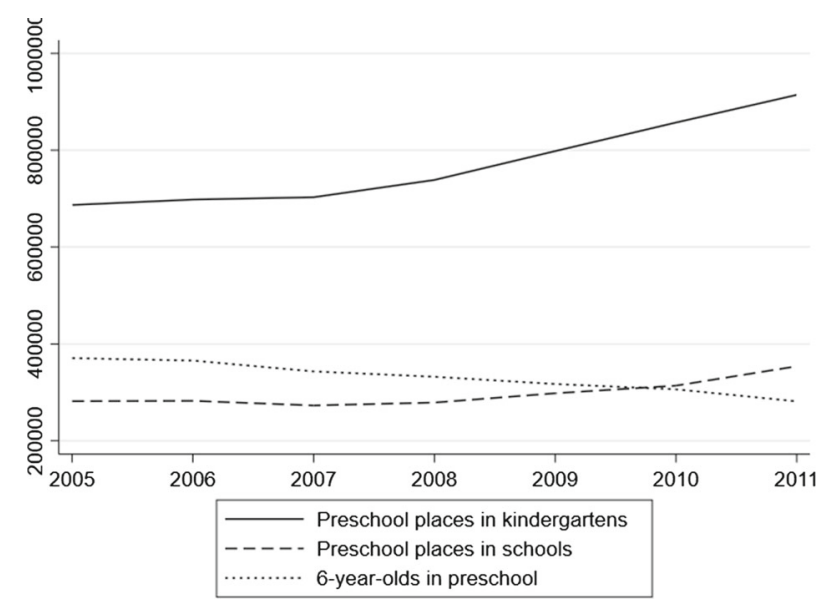

Fig. 3 Total number of preschool places

total number of preschool places available in a region. As we are interested in the number of preschool seats available for 3- to 5-year-olds, considering only the total number of preschool places ignores the fact that a (declining) share of the 6-yearolds is enrolled in preschool. In fact, an important element of the reform is that an increasing share of 6-year-olds moves into primary schools and that these children thereby leave a growing number of preschool seats available for 3- to 5-year-olds. We therefore subtract the number of 6-year-olds in preschool from the total number of preschool places to arrive at the total number of available places for 3-to 5-year-olds. At the national level, Fig. 3 shows the three sources of information used to construct the total number of available preschool places variable: (1) places in kindergartens, (2) (estimated) places in preschool classes in primary schools, (3) number of 6-year-olds in preschool. Figure 4 presents the preschool supply variable that is central in our analysis. We use the ratio of the preschool places available to 3- to 5-year-olds to the number of 3- to 5-year-olds in the region as the main treatment variable in the analysis. There is significant variation between regions in the increase in the ratio of preschool places to 3- to-5-year-olds between 2008 and 2011 (see Fig. 5; the development of the ratio variable is plotted for each region in Appendix Fig. 7).

\section{Results}

\subsection{Effects on preschool attendance}

The increased availability of preschool seats may increase maternal employment if the reform generated an increase in preschool attendance. Following a strategy similar to Berlinski et al. (2009), we estimate the effects of preschool supply on attendance at the region level (see Table 2, Panel A). ${ }^{15}$ We regress the change in the share of 3 - to

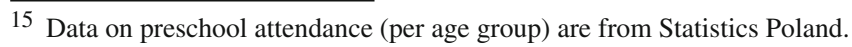




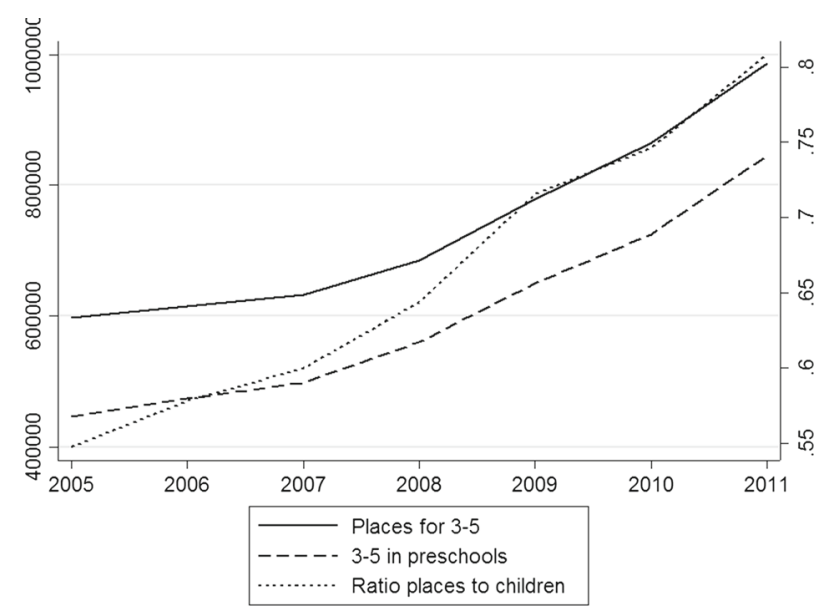

Fig. 4 Preschool places available to children aged 3-5

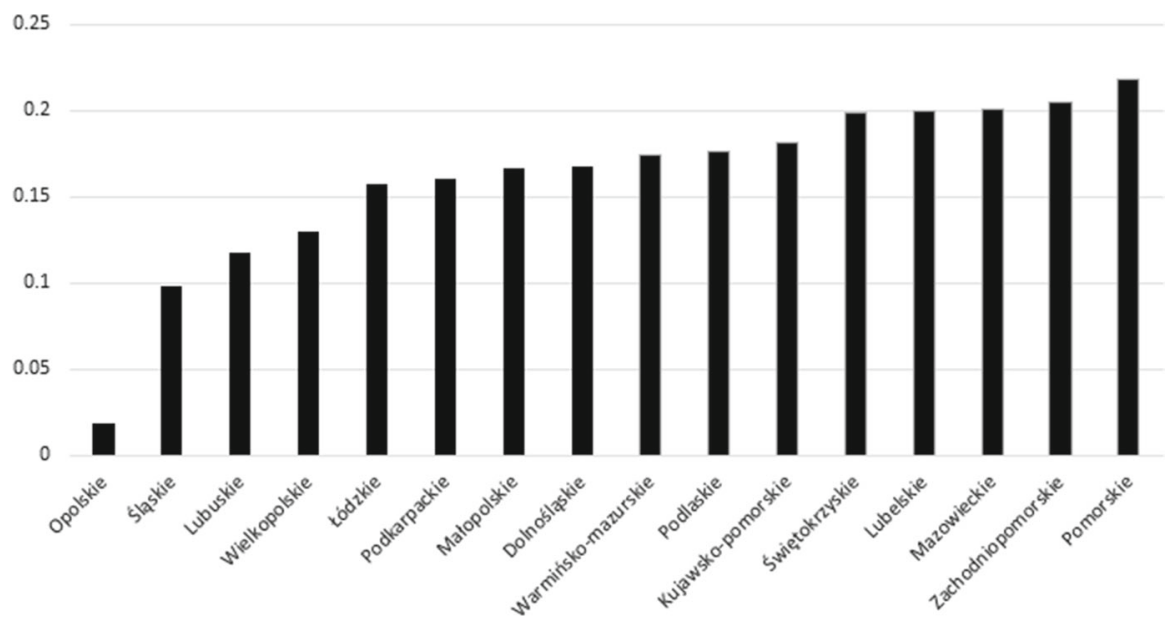

Fig. 5 Increase in preschool places by region (2008-2011)

5-year-olds in preschools on the change in the ratio of the preschool places available to 3- to 5-year-olds while including region and year fixed-effects (model 1).

We further use the DD specification presented by equation (1) to estimate the effect of preschool availability on attendance rates in models 2 and 3 (the DD model 3 includes region-specific time trends). The estimates show that for every 10 additional available places, about 5 additional children attend preschool. The effects are largest for 5-year-olds, which is in line with the statutory right given to 5-year-olds to attend preschool. However, the effects are also significant and sizable for mothers of 3- to 4-year-olds.

In Panel B of Table 2, we test the link between the number of 6-year-olds leaving pre-school and the number 3- to 5-year-olds entering preschool. On the left-handside, we have the change in the number of children aged 3-5 in pre-school while the 
treatment variable is defined as the change in the number of 6-year-olds in preschool. The final column with the DD specification that includes region-specific time trends shows that for each 6-year-old less in preschool (but in primary school instead), there is one additional 3- to 5-year-old in preschool. This suggests that the switch from preschool to school among 6-year-olds led to more spaces being available for children aged 3 to 5 . The effect is sizable, suggesting that rationing of preschool places plays an important role in Poland (consistent with the discussion in Sect. 2.1). Given that the reform led to a significant increase in the use of preschool services, the reform may also have substantially facilitated mothers of young children to return to work.

\subsection{Effects on maternal employment}

The main estimation results of the DD and DDD models are presented in Table 3. The upper panel shows the effects on employment and the lower on working hours. We define several alternative model specifications (as in e.g. Nollenberger and RodríguezPlanas (2015). The DD effect (model 1) is estimated by the interaction between postreform dummy and the ratio of preschool places to 3- to 5-year-olds [Eq. (1)]. The DDD model estimates the effect through the triple interaction between the post-reform dummy, the ratio of preschool places to 3- to 5-year-olds and treatment group status (Eq. (2)). The DDD model 2 includes region-specific time trends. DDD model 3 is our main DDD specification; this model does not include region-specific time trends but does introduce interactions between treatment group status and region, year fixed effects and personal characteristics. In model 4, region-specific time-trends are reintroduced along with a linear trend for the treatment group mothers (models 5-7 are based on a different comparison group, see below).

The results indicate that the effects of increasing preschool availability are statistically insignificant and negative in the DD model, but positive and statistically significant in the DDD models. This is similar to previous studies such Nollenberger and Rodríguez-Planas (2015) for Spain and Cascio and Schanzenbach (2013) for US, reporting statistically significant positive effects in the DDD model but not in the DD model; below we discuss more extensively the reasons for the difference between the DD and DDD results. The effect size becomes larger once we control for interactions between region- and year-specific fixed effects, personal characteristics and treatment group status in model 3. ${ }^{16}$ Similar to the estimates of Nollenberger and RodríguezPlanas (2015), including region-specific time trends (model 4) does not seem to change the coefficient estimates. The coefficient estimate suggests that a $10 \%$ point increase in the ratio increases employment probability by $4.2 \%$ points. ${ }^{17}$ The effect on working hours reflects the substantial effect on employment. Average working hours for working women prior to the reform was 38.5 and the average for all women was 24 .

\footnotetext{
16 Since the variation is limited in variables about the number of other children in different age categories, we also tested the model by omitting these variables and their interactions. The results change very little. We made a similar test by dropping the dummy for native status and its interactions and again the main results hardly change.

17 The average ratio in the treated sample is around 0.64 in 2008 and average employment is 0.67. Based on these values, we can calculate the elasticity of employment with regard to the ratio of preschool places to the number of 3- to 5-year-olds to be around 0.39 .
} 
Table 2 The impact of preschool supply on preschool attendance

\begin{tabular}{llll}
\hline Model & 1 & 2 & 3 \\
\hline Estimator & OLS & DD & DD \\
\hline
\end{tabular}

Panel A: Share attending preschool

Age 3-5

Treatment

$\begin{array}{ll}0.4821 * * * & 0.5707 * * * \\ (0.0564) & (0.1065)\end{array}$

$0.5336 * * *$

$(0.0564)$

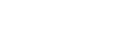

(0.1091)

Age 3

Treatment

$\begin{array}{ll}0.3870 * * * & 0.4719 * * * \\ (0.0713) & (0.1206)\end{array}$

0.5071 *** $*$

(0.1300)

Age 4

Treatment

$\begin{array}{ll}0.4451 * * * & 0.4317 * * * \\ -0.0702 & (0.1259)\end{array}$

$0.4279 * * *$

$0.8904 * * *$

(0.1241)

Age 5

Treatment

$$
0.6462 * * *
$$

(0.2476)

$0.7619 * * *$

(0.1232)

$(0.2476)$

(0.2607)

Panel B: Number attending preschool

Age 3-5
6-year-old in preschool

$$
-1.2096^{* * *}
$$$$
-2.6362 * * *
$$$$
-1.0017 * * *
$$$$
\text { (0.3814) }
$$

Age 3

6-year-old in preschool

$$
\begin{aligned}
& -0.2452^{* * * *} \\
& (0.0720)
\end{aligned}
$$$$
-0.1442 *
$$$$
\text { (0.0794) }
$$$$
\begin{aligned}
& -0.8202 * * * \\
& (0.2544)
\end{aligned}
$$$$
112
$$

Region FE

Year FE

Region trends

$$
\begin{array}{ll}
-0.6379^{* * * *} & -0.1856^{*} \\
(0.1104) & (0.0980)
\end{array}
$$

0.0691

$$
-0.5701 * * *
$$$$
\text { (0.1170) }
$$

-1.4282 ***
$(0.2013)$
112
+
+
-

112

$+$

$+$

$+$

Robust standard errors in parentheses. Panel A: The treatment variable is the change in the ratio of preschool places to the number of 3- to 5-year-olds (OLS) interacted with reforms years (DD); the dependent variable is the change in the (age-specific) share of children attending preschool. Panel B: The treatment variable is the change in the number of 6-year-olds in preschool (OLS) interacted with reforms years (DD); the dependent variable is the change in the number of (age-specific) number of children in preschool $* * * p<0.01 ; * * p<0.05 ; * p<0.1$ 
A $10 \%$ increase in the ratio appears to increase working hours for all women by 1.2 $\mathrm{h}$, which corresponds to a $5 \%$ increase in female labour supply. The effect found on working hours appears to be driven by the decision to enter the labour market rather than an increase in working hours of employed mothers. Table 7 in Appendix estimates the working hours effects for only working hours and the reported results show no statistically significant effects for mothers or fathers. This result is probably due to the low incidence of part-time work which is reflected in the average working hours of employed women being close to the full-time equivalent of $38.5 \mathrm{~h}$.

While we use mothers with the youngest child aged 7 to 8 as the control group in models 2 to 4, we examined whether the results are sensitive to the choice of control group. We test whether the results change based on the control group by using mothers with a youngest child aged 7 to 9 in model 5,9 to 10 in model 6 and 10 to 12 in model 7 . The results show that the coefficient estimates change only marginally when mothers with slightly older children are used as the control group. ${ }^{18}$

We also tested whether the effects differ depending on our choice of treatment and control years. Throughout our main specifications, we used the years 2005 to 2008 as our control years and 2009 to 2011 as our treatment years. 2009 is a special case since treatment begins in September. In Appendix Table 9, we extend the sample to all years between 2003 and 2013 in column 1. In column 2, we limit the control years to 2007 and 2008. In column 3, we use all available control years starting in 2003. In the final column, we allow treatment years to continue up to 2013. The results remain relatively stable throughout. The main difference is seen when including years 2012 and 2013, where the coefficient becomes smaller. This seems in line with the roll-back of the reform that began in 2012.

Finally, we also examined whether the results are sensitive to a change in our treatment variable by constructing the treatment variable as the ratio of all preschool places (i.e., without subtracting the seats occupied by 6-year-olds) to the number of 3 - to 5-year-olds in the region. The model using this alternative treatment variable leads to qualitatively similar employment effect estimates (see Appendix Table 10). However, as expected, the effect sizes become smaller since we do not exploit all relevant variations in changes in preschool availability.

Our DDD results point out that the reform significantly increased maternal employment. One may expect that the effect of increased employment among mothers may lead to a negative effect on the employment of fathers through an income effect. For example, Bettendorf et al. (2015) found that a childcare subsidy reform in the Netherlands increased female employment but decreased male working hours. We test whether fathers are affected in the Polish setting by estimating the same DD and DDD models for fathers: the results are presented in Table 11. None of the models report significant effects for male employment. Since working hours flexibility is low

\footnotetext{
18 Because leave and childcare reforms in the post-reform period (see Sect. 2.2) may have affected the employment of mothers of younger-aged children, using mothers with a youngest child aged 1 to 2 as a control group is problematic. However, the results are presented in Appendix Table 8. The coefficient size reduces to less than half the size of the other estimates and turns statistically insignificant. When we tested a model where mothers with the youngest child aged 1 was the control group, the effect for the 3-5 age group remains statistically significant and similar in size to other models. The decline in the effect size appears to be largely driven by mothers of 2-year-olds.
} 


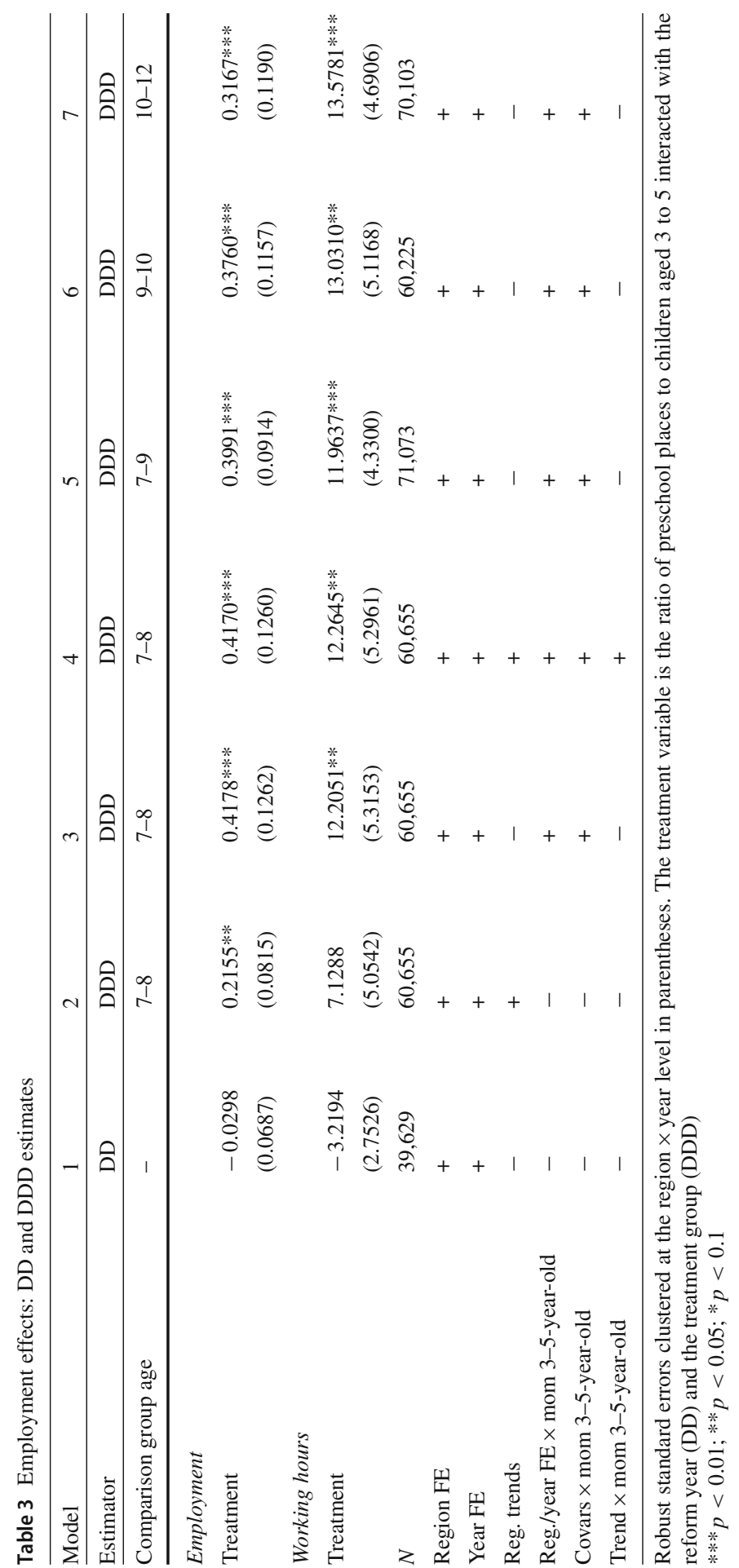


in Poland (Plomien 2009), it seems unlikely that they would be able to adjust working hours in response to increased female employment even when faced with increased household consumption.

While the DDD results thus far suggest that maternal employment increased due to the increased availability of preschool services, the results hinge on the common trend assumption. If employment rates of mothers with older children who comprise our control group underwent a shock at the same time, our results will be biased. This potential threat to validity is especially relevant in our study since the years of the reform coincide with the financial and later sovereign debt crises in Europe which are likely to have had negative effects on employment. In Table 4 (panel A), we present the results of several placebo tests of our main DDD model. In the first four columns, we present results of models using mothers of children aged $6,7,8$ as well as 7-8 combined as the treatment group. We adjust the control group according to mothers with youngest children up to 2 years older. In addition, on the rightmost column of Table 4, we show the results of a placebo reform that is assumed to have gone into effect in September 2007 (actual treatment years 2009-2011 are excluded). None of the placebo estimates appear to be statistically significant, confirming that our main DDD estimates capture an increase in employment that is unique to the mothers in the actual treatment group.

There is a large difference between the DD and the DDD results, indicating that there are significant cross-regional variations in the development of female employment during the relevant years. This is in line with Fig. 2 which suggests that the strong upward trend in female employment in Poland ended with the onset of the financial crisis in 2008-2009. To test whether this explains the difference between the DD and DDD results, we performed a series of placebo tests, similar to the ones discussed above for the DDD models (Table 4, Panel B). The results of these placebo tests point out the limitations of the DD models in our context: our treatment measure is significantly related to the employment of mothers with a youngest child aged 7-8. This indicates that regions that experienced a larger increase in preschool availability were hit harder by the economic crisis. We further investigated whether the crisis is causing the difference between DD and DDD results by estimating the DD and DDD models using a single year before and after treatment (i.e., excluding the crisis years). More specifically, we use 2007 or 2008 as the control year and 2011 as the treatment year. The results are presented in Appendix Table 12. The DDD estimates are still larger but the effects on employment are significantly positive in the DD estimates as well, which suggests that the regional variation in the impact of the crisis explains the differences in our baseline estimates between DD and DDD models.

\subsection{Heterogeneous effects}

While our results indicate that the reform had a positive effect on mothers' employment, we can look further into sub-samples to test whether the effect is driven by a particular group. Table 5 shows the effects on the employment probability and working hours of various sub-samples of mothers. We use the specification in model 3 of Table 3 in all estimations. 


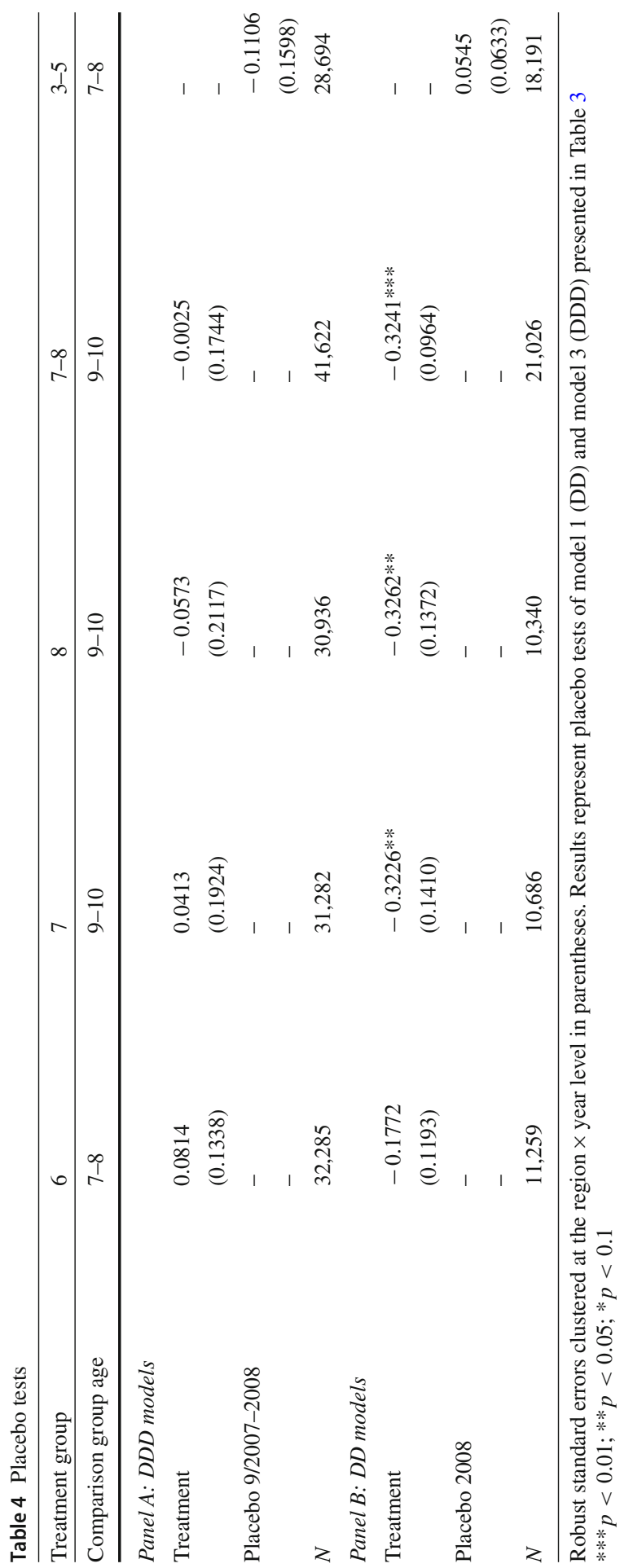




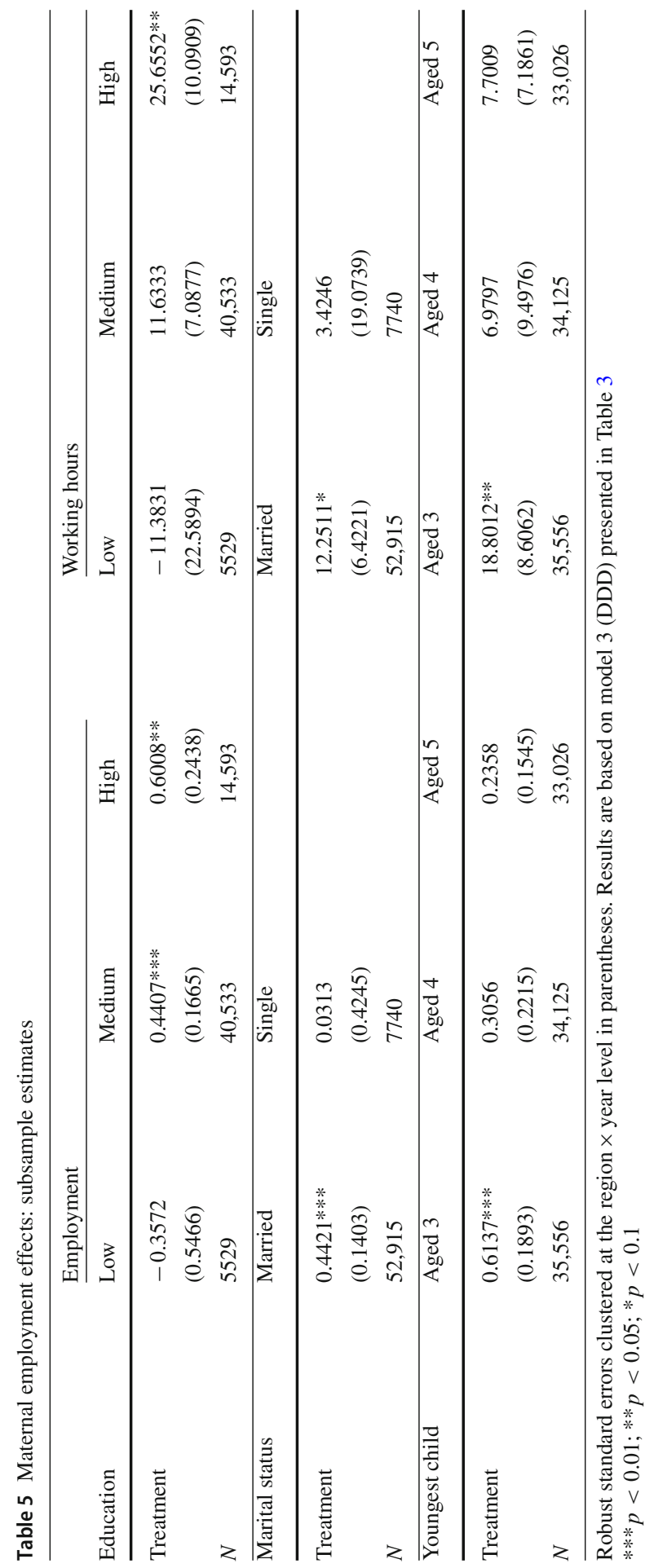


According to the results in Table 5, the treatment effect is stronger for higher educated women. This result seems to be inconsistent with most other studies. A potential explanation is that the availability of other forms of care is low in Poland even for highly educated mothers. Since they are likely to earn the highest wages in the labor market, the impact of the reform is larger for this group. Simultaneously, cultural barriers for lower educated women might explain their lack of response to preschool availability. We also find stronger effects for married women, but the number of single women in the sample is relatively low.

When we estimate the effect for mothers with children at different ages in the last panel of the table, we find a stronger effect for mothers of 3-year-olds. A potential reason is that the expansion of preschool places benefited 3-year-olds' mothers most. Preschool attendance was already relatively high for 5-year-olds in the pre-treatment period and there may be more mothers willing to work but unable to find preschool services among mothers of 3-year-olds. It should be noted that children can enroll in preschool from age 3 onward (conditional on sufficient availability) and that parental leave during the relevant period was around 3.5 years: age 3 therefore represent a critical transition phase, both for children and mothers. Hence, a larger share of mothers of 3-year-olds may be able to return to the labour market when more preschool seats become available.

To further examine age-specific effects of the reform we replaced the ratio of preschool places to the number of children with the actual attendance rate as the treatment variable. We consider the ratio of preschool places as a better treatment indicator since the policy reform had a direct effect on available places and not coverage. Moreover, the attendance rates may be considered endogenous as attendance rates could be demand driven. However, the results of the DD and DDD regressions based on the region-specific attendance rates show little qualitative differences from the main results: see Appendix Table 13. Nevertheless, one advantage of using the attendance rate is that we can calculate age-specific attendance rates instead of relying on seats available for the total group of 3- to 5-year-old children; these age-specific attendance rates can be used to estimate age-specific effects. Consistent with the results discussed above, Appendix Table 14 shows that the treatment effects are larger for mothers of 3 -year-olds and that mothers of 4-year-olds are not affected by the reform. In contrast to the results based on the number of preschool places, these results show that the employment of mothers of 5-year-olds significantly increased. This may be expected given that a statutory right to preschool was provided to children aged 5 .

Lastly, using attendance rather than coverage as the treatment variable allows us to test whether the switch from preschool to school affected the employment of the mothers of 6-year-olds. As 6-year-olds are either in preschool or school, we do not expect a substantial effect of the reform on the employment rate of mothers of this age group. The results show that, while there is a significantly positive effect in the DD specification, the preferred DDD models largely indicate that leaving preschool for school had no statistically significant effects on the employment of mothers of 6-year olds (Appendix Table 14). 
Table 6 ECEC and maternal employment: an overview of the evidence

\begin{tabular}{|c|c|c|c|c|}
\hline & Country & $\begin{array}{l}\text { Employment effect of } \\
\text { a } 10 \% \text { increase in } \\
\text { childcare use }\end{array}$ & Methodology & $\begin{array}{l}\text { Pre-treatment } \\
\text { employment level }\end{array}$ \\
\hline \multicolumn{5}{|l|}{ Literature } \\
\hline $\begin{array}{l}\text { Bauernschuster and } \\
\text { Schlotter (2015) }\end{array}$ & Germany & 3.7 & IV and DD & 0.45 \\
\hline $\begin{array}{l}\text { Bettendorf et al. } \\
\text { (2015) }\end{array}$ & Netherlands & 1.5 & DD & 0.68 \\
\hline $\begin{array}{l}\text { Havnes and Mogstad } \\
\text { (2011) }\end{array}$ & Norway & 0.6 & DDD & 0.25 \\
\hline Lundin et al. (2008) & Sweden & 0 & DD & 0.70 \\
\hline $\begin{array}{l}\text { Nollenberger and } \\
\text { Rodríguez-Planas } \\
\text { (2015) }\end{array}$ & Spain & 2 & DDD & 0.35 \\
\hline Blanden et al. (2016) & England & 0 & DDD & 0.72 \\
\hline $\begin{array}{l}\text { Berlinski and Galiani } \\
\text { (2007) }\end{array}$ & Argentina & 1.05 & DD & 0.39 \\
\hline $\begin{array}{l}\text { Cascio and } \\
\text { Schanzenbach } \\
\text { (2013) }\end{array}$ & United States & 0 & DDD & 0.40 \\
\hline Our results & Poland & 4.2 & DDD & 0.66 \\
\hline
\end{tabular}

The exact treatment variable varies by study, which should be taken into account when comparing the estimates provided in the table. For the Netherlands study, we calculate the increase in childcare use during the treatment period using the Trade Organization Childcare Data (Brancheorganizatie Kinderopvang Factsheet 2015). We base our calculation on the numbers for the 0-3 category. For the remainder of the studies, we calculated the values using summary statistics if a calculation was not given by the authors

\subsection{Effects of ECEC reforms in Europe}

Table 6 summarizes our results alongside the results from the previous quasiexperimental studies on the maternal employment effects of ECEC. The largest effects appear to be found in Poland and Germany, where per percentage point increase in ECEC availability or use (in case of Germany), mothers' employment rises by around $0.4 \%$ points. The dead-weight loss was greatest in Norway, where a $57 \%$ point increase in childcare use led to a $4 \%$ point increase in employment (Havnes and Mogstad 2011). There was also no employment effect in Sweden from a decrease in childcare prices according to Lundin et al. (2008), but that seems hardly surprising given the limited increase in childcare use. The results from the Netherlands and Spain are in between the results from Poland and Germany on the one hand and the US and the Nordic countries on the other hand. For example, in the Netherlands a 10\% increase in childcare use corresponded to an employment increase of around $1.5 \%$ points.

There may be a combination of factors explaining the heterogeneity in empirical findings. First, some studies suggest that effect sizes decline with the pre-reform maternal employment rate (Lundin et al. 2008; Bauernschuster and Schlotter 2015). However, other studies do not confirm this pattern. Second, the responsiveness of 
maternal employment to ECEC reforms may hinge critically on the availability of alternative forms of childcare services: several studies (Blanden et al. 2016; Cascio and Schanzenbach 2013; Havnes and Mogstad 2011) attribute the lack of strong effects on maternal employment from public childcare and preschool expansions to the high availability of other forms of childcare prior to the expansion. Basically, the expansion of public ECEC services may substantially crowd out existing (formal or informal) childcare arrangements. For instance, studies from the US where private preschools are already available generally find weak employment effects from preschool expansions targeted at older children (Cascio 2009; Fitzpatrick 2012). Similarly, effects may be limited due to crowding out of informal childcare arrangements (Havnes and Mogstad 2011). Although the use of informal care is relatively common in Poland, a very high share of Polish children below the primary school age are cared for only by their parents (as discussed in the last paragraph of Sect. 2.2): for these families, there will be no crowding out of alternative care arrangements. This may (partially) explain the rather large effect sizes reported in our study.

It is striking that the estimated effects of both the German and Polish ECEC reform are considerably larger than other estimates. The two cases share important similarities. First, both reforms concern an expansion of services for children from age three until primary school entry. ${ }^{19}$ Second, during the relevant evaluation periods, the childcare infrastructure for children below the age of three was highly underdeveloped in Poland and West Germany (where the employment effects are found). Third, the total duration of job-protected leave is lengthy in both cases (three and three and a half years in Germany and Poland, respectively). We conjecture that women in Poland and West Germany preferring to return to their job (near) the end of parental leave were more likely to do so due to the increased availability of preschool places for their 3-year-olds. Interestingly, the results from Norway (Havnes and Mogstad 2011) pointing out that the expansion of preschool services for children aged 3 to 6 hardly affected maternal employment and mostly crowded out informal care arrangements are consistent with the childcare-parental leave interaction explanation. As the period of leave was rather short (12-18 weeks) in Norway, mothers who wished to return to the labor market at the end of leave had to rely on informal care arrangements. It is then also plausible that an expansion of preschool for 3- to 6-year-olds resulted in a crowding out of these informal care arrangements. Recent evidence indicates that increasing the duration of parental leave has generally limited effects on maternal employment in the medium and long run, unless mothers do not return to work at the end of the job protection period (Lalive et al. 2013; Schönberg and Ludsteck 2014; Mullerova 2017). The latter scenario is of course more likely when limited childcare services are available. This once more suggests that interactions between childcare policies and parental leave schemes are important. Overall, the evidence indicates that the maternal employment effect of a childcare expansion depends crucially on whether this allows mothers to use parental leave more effectively as a bridge to return to work.

\footnotetext{
19 Bauernschuster and Schlotter (2015) evaluates the effects of the 1996 introduction of a legal claim to a kindergarten place.
} 


\section{Conclusions}

This study provides evidence of positive maternal employment effects of a (pre)school reform in Poland. Our results indicate a significant and sizable impact of an expansion of preschool services for 3- to 5-year-olds on maternal employment: a 10\% points increase in the ratio of preschool seats to preschool-aged children increases maternal employment by around $4 \%$ points. The estimated effect sizes are large compared to most of the estimates reported in the existing quasi-experimental literature on this topic. This result may be rather striking as in Poland opportunities for flexible work are limited and cultural norms are not supportive of maternal employment. However, the sizable effect can be explained by an often overlooked policy interaction. In Poland, access to childcare services for children below the age of three is limited and parental leave is lengthy (more than 3 years). It is plausible that the increased availability of preschool seats for 3- to 6-year-olds allowed mothers to return to work at the end of the parental leave period. This explanation is consistent with our results indicating that the overall positive effect is mainly due to the increase in employment of mothers of 3-year-olds. Such policy interactions deserve more attention in future research.

A unique feature of the Polish reform is that the reform is targeted at lowering the primary school starting age. Lowering the age for compulsory school age appears to have the unintended consequence of expanding preschool seats available to younger children. While 6-year-olds left their preschool chairs vacant, more 3- to 5-year-olds enrolled in preschool and more mothers of these younger children entered employment. Our findings indicate that changing the primary school starting age can be de facto a preschool reform. Such a school reform may affect maternal employment decisions, not (only) among mothers of school-aged children, but among mothers of preschoolaged children as more preschool seats become available. Given the substantial positive maternal employment effects of the 2009 Polish (pre)school reform, the decision by the new government to move the school starting age back from 6 to 7 is likely to generate negative effects on employment of mothers with preschool-aged children.

While our findings indicate that the reform significantly increased maternal employment, it should be stressed that it is not clear whether societal benefits outweigh the societal costs. The results of cost-benefit analysis of preschool policies depend crucially on the impact on children's development (van Huizen et al. 2019), and child outcomes of preschool expansions are determined by the quality of the provision (van Huizen and Plantenga 2018). On the one hand, one of the reasons to implement the (pre)school reform were the assumed beneficial child development effects. On the other hand, politicians and stakeholders opposing the reform claimed that children were harmed by reform (Herbst and Strawiński 2016). In this case it is unclear if children's human capital was positively or negatively affected. However, if preschools would be of low quality and the system would be inadequate for the youngest children, the employment effects can be expected to be weaker as parents may learn this and take this into account in their employment decision. Hence, serious concerns for policy makers considering such a reform are whether schools are ready to take in an additional cohort of children and whether preschools are able to provide high-quality services to younger aged children. 
Acknowledgements We thank two anonymous referees and the editor for carefully reading the original version of this manuscript and for providing the helpful comments that serviced to greatly improve the content and exposition of this article.

Funding This study is part of the CARE project (Seventh Framework Programme), funded by the European Union (Grant No. 613318).

\section{Compliance with ethical standards}

Conflict of interest The authors declare that they have no conflicts of interest.

Open Access This article is licensed under a Creative Commons Attribution 4.0 International License, which permits use, sharing, adaptation, distribution and reproduction in any medium or format, as long as you give appropriate credit to the original author(s) and the source, provide a link to the Creative Commons licence, and indicate if changes were made. The images or other third party material in this article are included in the article's Creative Commons licence, unless indicated otherwise in a credit line to the material. If material is not included in the article's Creative Commons licence and your intended use is not permitted by statutory regulation or exceeds the permitted use, you will need to obtain permission directly from the copyright holder. To view a copy of this licence, visit http://creativecommons.org/licenses/by/4.0/.

\section{Appendix}

See Figs. 6 and 7 and Tables 7, 8, 9, 10, 11, 12, 13 and 14.

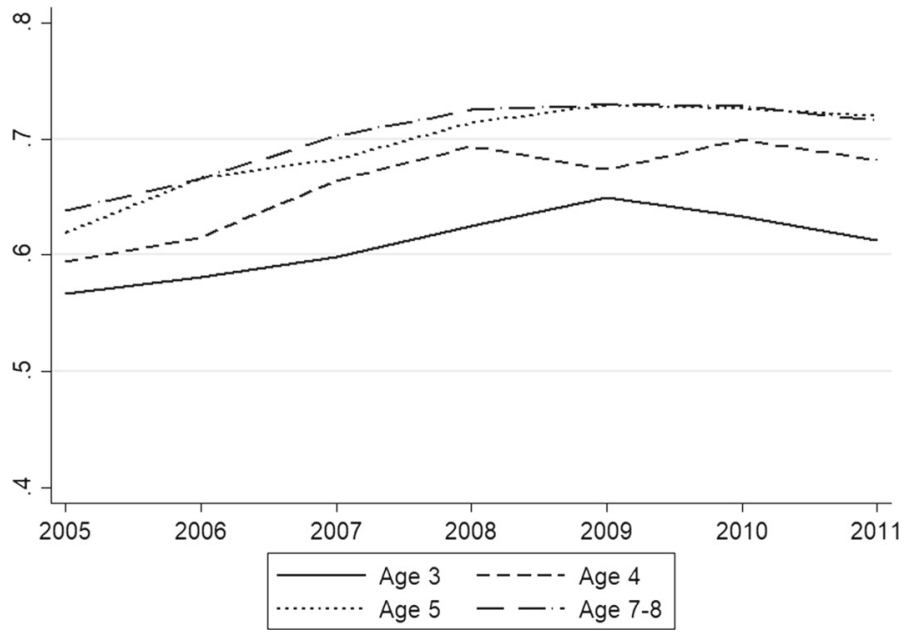

Fig. 6 Average weighted employment rates over time in LFS by youngest child age 


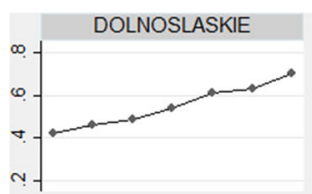

L?DZKIE

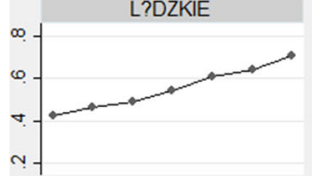

PODKARPACKIE
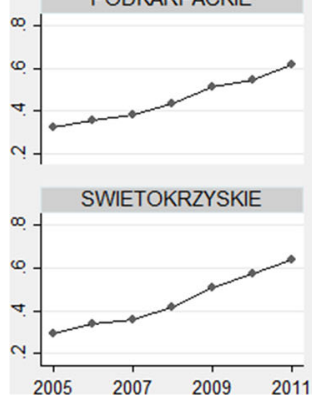

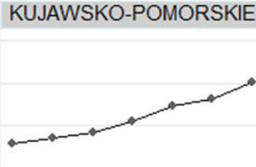

MALOPOLSKIE

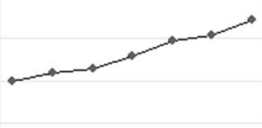

PODLASKIE

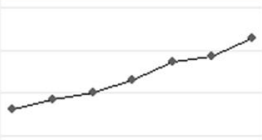

WARMINSKO-MAZURSKIE
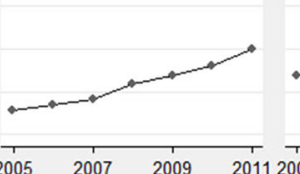

LUBUSKIE

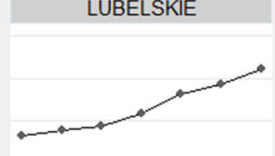

MAZOWIECKIE

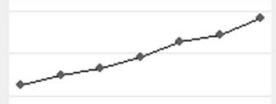

POMORSKIE

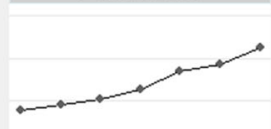

WIELKOPOLSKIE

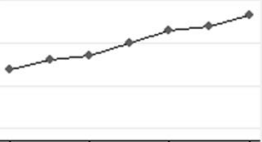

ZACHODNIOPOMORSKIE

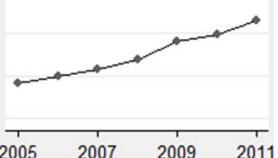

Fig. 7 Ratio of preschool places to 3 to 5 -year-olds by region 


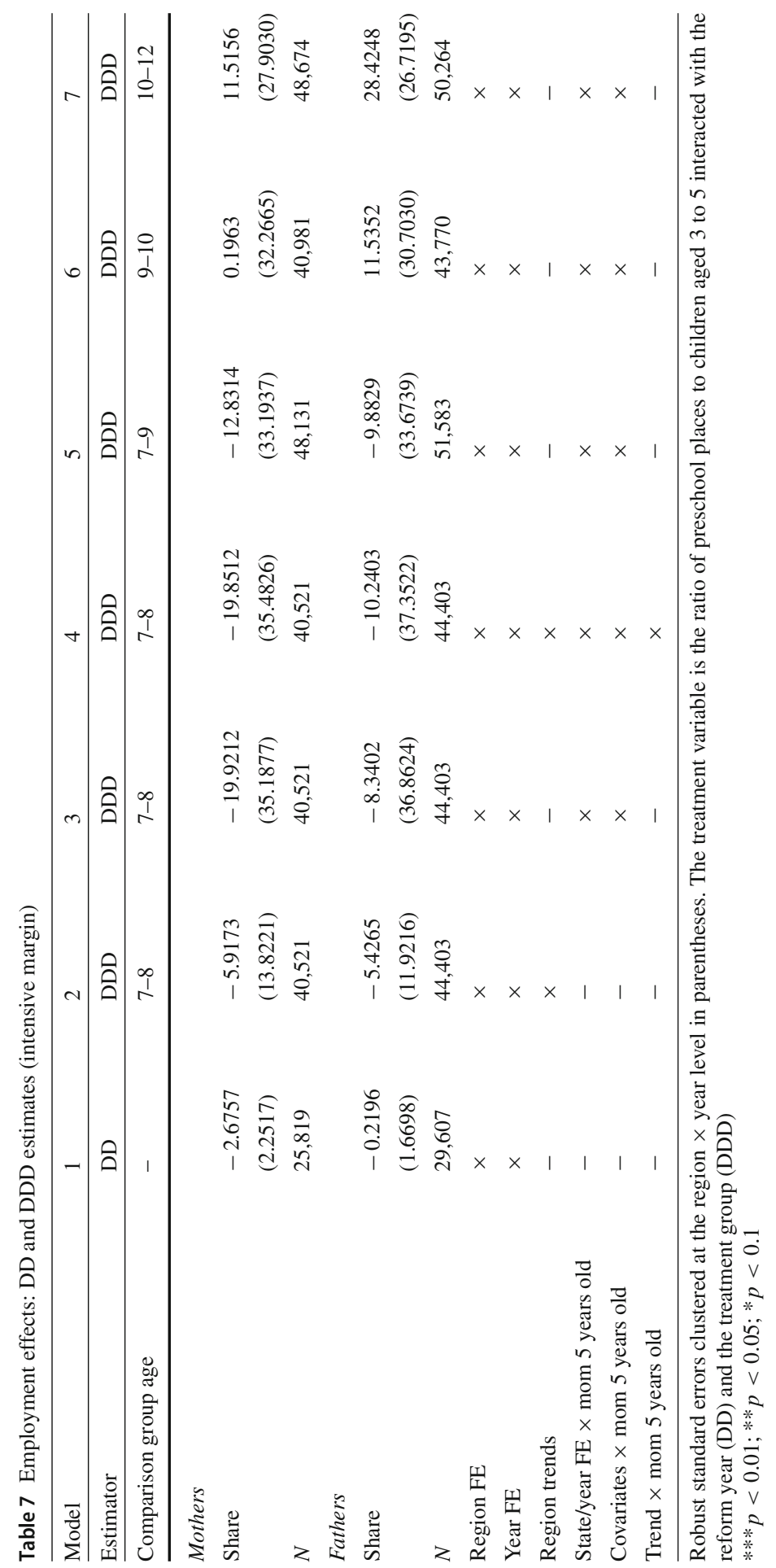


Table 8 DDD results: mothers of 1-2 aged children as a comparison group

\begin{tabular}{llll}
\hline Comparison group age & $1-2$ & 1 & 2 \\
\hline Treatment & 0.1856 & $0.4027 * * *$ & -0.0555 \\
& $(0.1130)$ & $(0.1283)$ & $(0.1684)$ \\
$N$ & 66,316 & 53,520 & 52,425 \\
\hline
\end{tabular}

Robust standard errors clustered at the region $\times$ year level in parentheses. Results are based on model 3 (DDD) presented in Table 3

$* * * p<0.01 ; * * p<0.05 ; * p<0.1$

Table 9 Alternative treatment and control years

\begin{tabular}{lllll}
\hline Treatment years & $2009-2013$ & $2009-2011$ & $2009-2011$ & 2009-2013 \\
\hline Control years & $2003-2009$ & $2007-2008$ & $2003-2009$ & $2005-2008$ \\
\hline $\begin{array}{l}\text { Employment } \\
\text { Treatment }\end{array}$ & $0.3527 * * *$ & $0.3654 * *$ & $0.4716^{* * *}$ & $0.2692^{* *}$ \\
& $(0.1173)$ & $(0.1493)$ & $(0.1153)$ & $(0.1258)$ \\
Working hours & $11.2100^{* *}$ & $11.7725^{*}$ & & 7.4723 \\
Treatment & $(4.6843)$ & $(6.9714)$ & $(4.6107)$ & $(5.3569)$ \\
& 91,134 & 45,104 & 64,789 & 87,000 \\
\hline
\end{tabular}

Robust standard errors clustered at the region $\times$ year level in parentheses. Results are based on model 3 (DDD) presented in Table 3

$* * * p<0.01 ; * * p<0.05 ; * p<0.1$ 


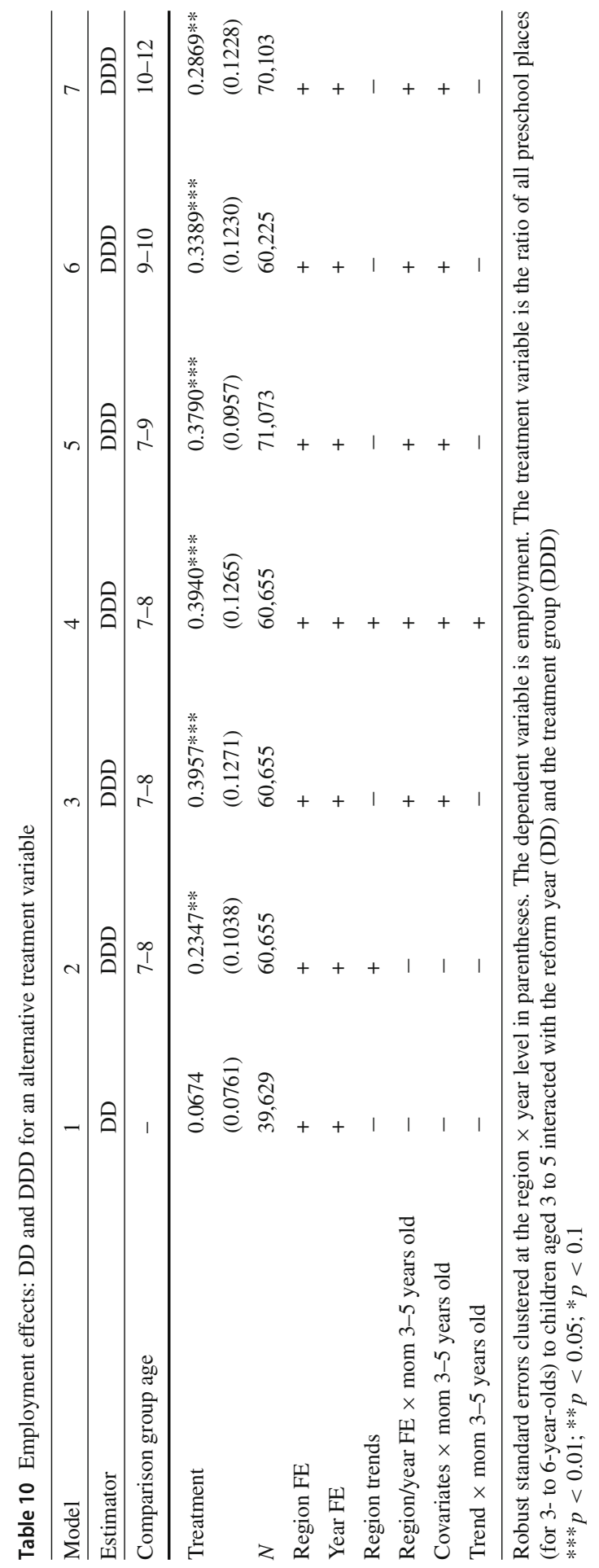




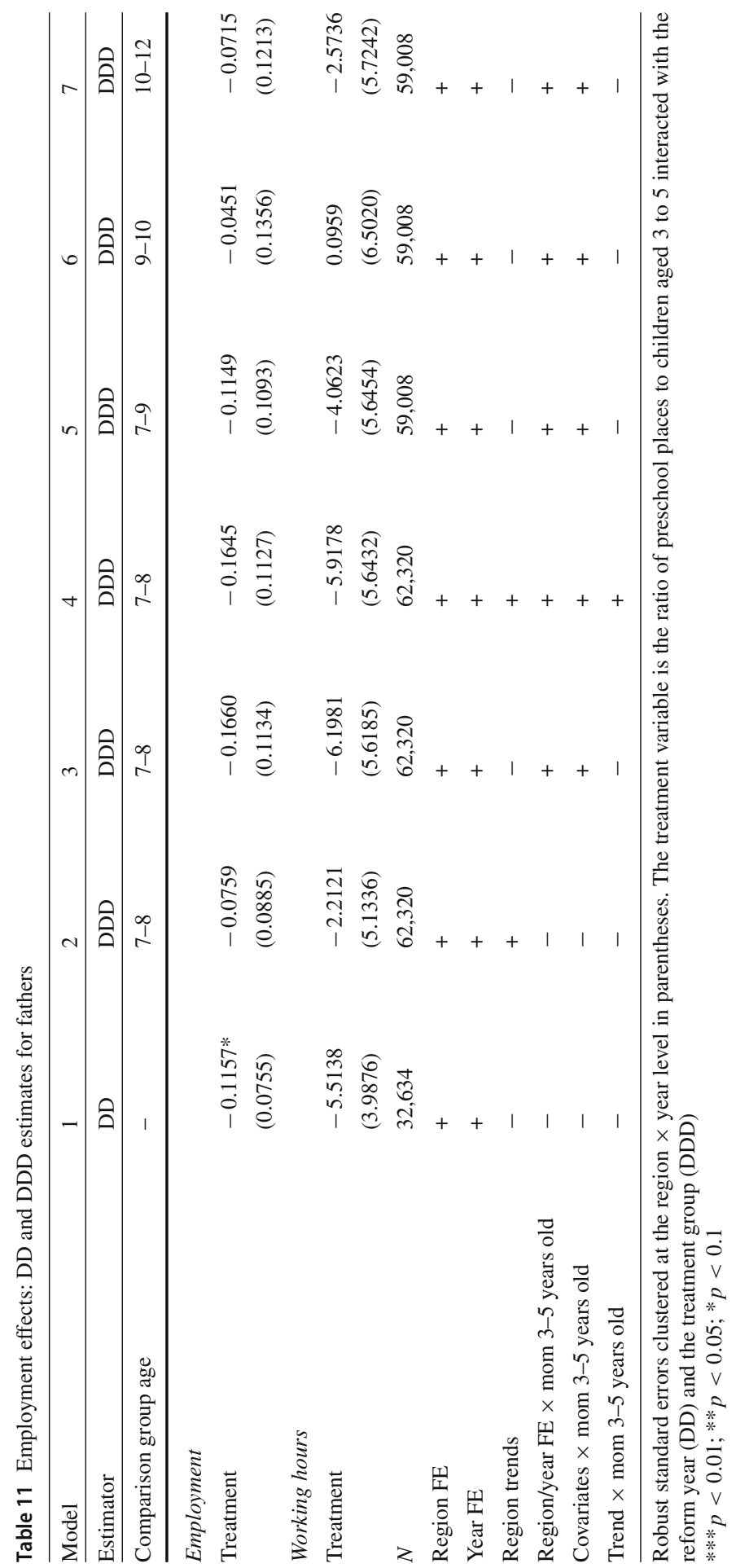


Table 12 DD and DDD estimates using single treatment and control years

\begin{tabular}{lllll}
\hline Estimator & DD & DD & DDD & DDD \\
\hline Control year & 2007 & 2008 & 2007 & 2008 \\
\hline Employment & & & & \\
Treatment & $0.5430 * * *$ & $0.3507 * * *$ & $0.8467 * * *$ & $0.5005^{* * *}$ \\
& $(0.0725)$ & $(0.0857)$ & $(0.1024)$ & $(0.1569)$ \\
$N$ & 13,091 & 12,891 & 19,655 & 19,274 \\
\hline
\end{tabular}

Robust standard errors clustered at the region $\times$ year level in parentheses. The treatment year is 2011 in all models. The DD models correspond to model 1 in the main results tables while the DDD models correspond to model 3

$* * * p<0.01 ; * * p<0.05 ; * p<0.1$ 


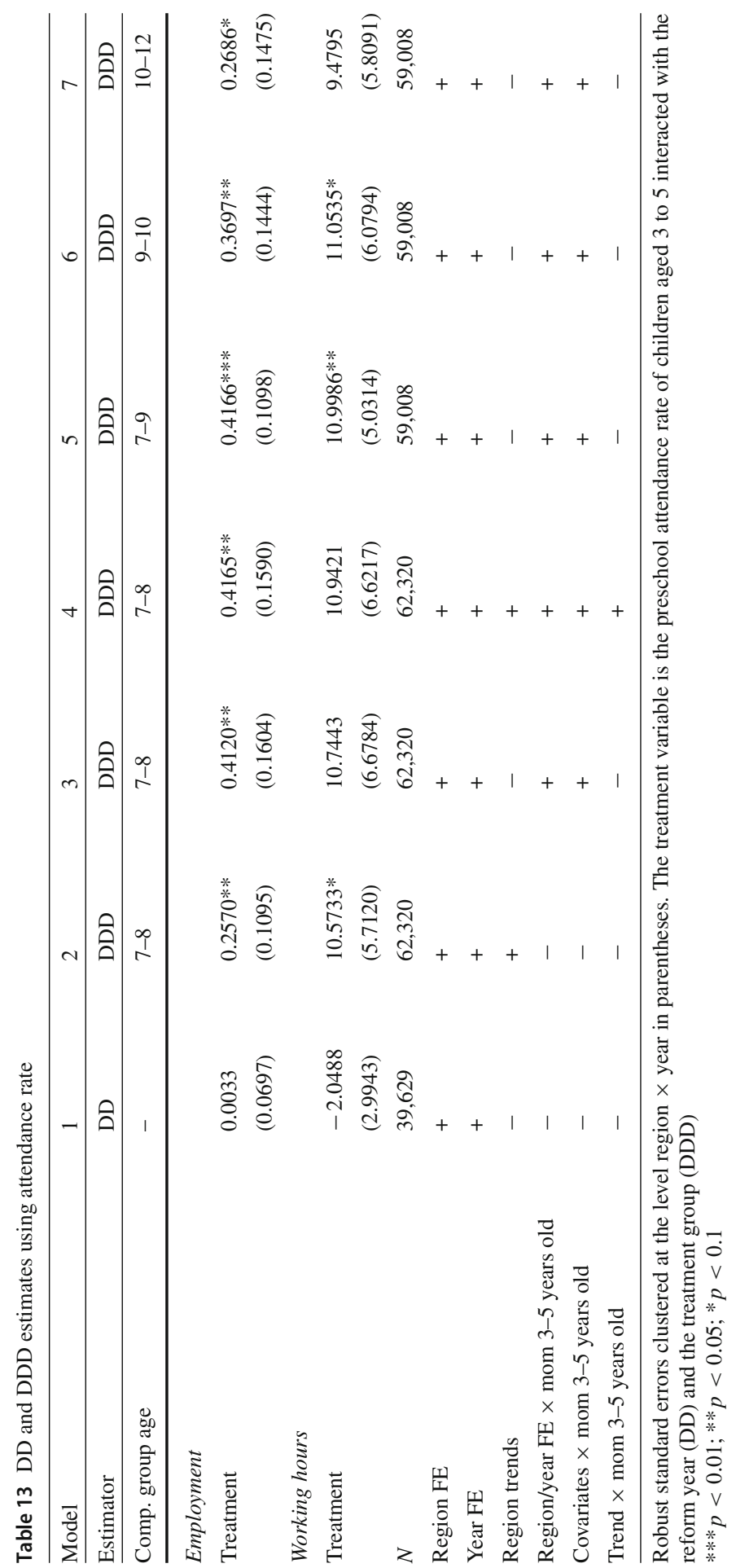




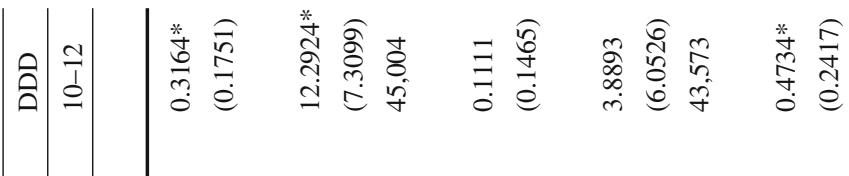

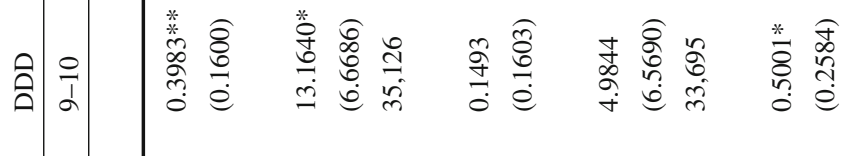

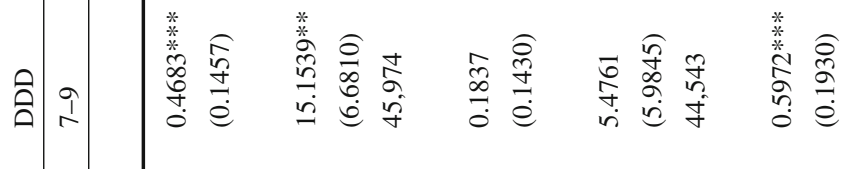

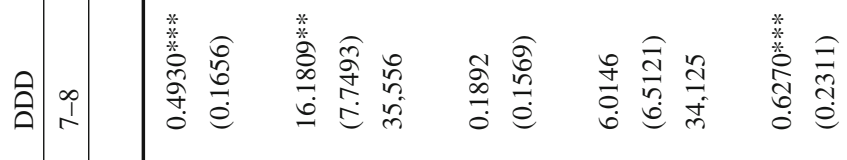

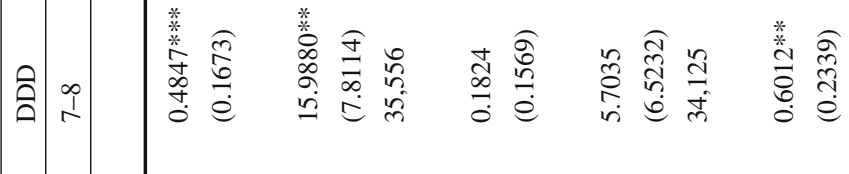

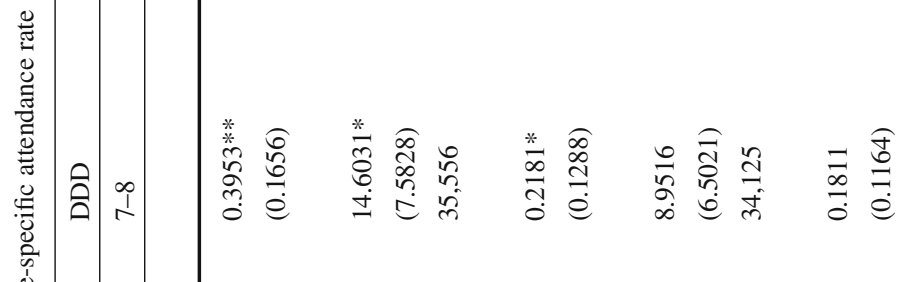

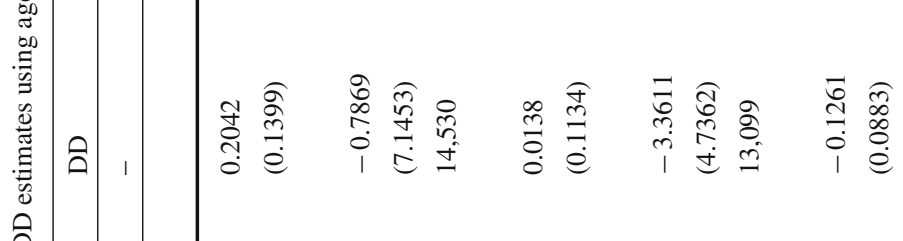

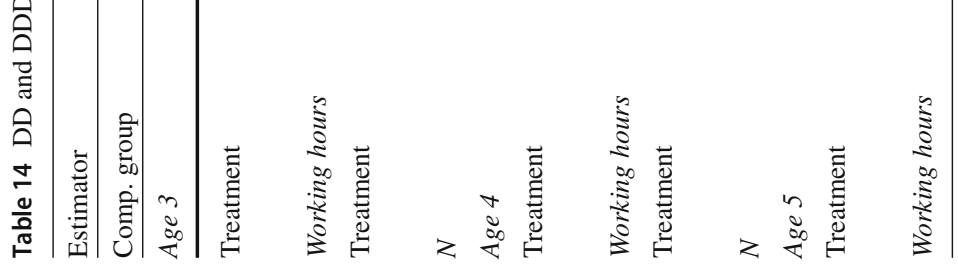




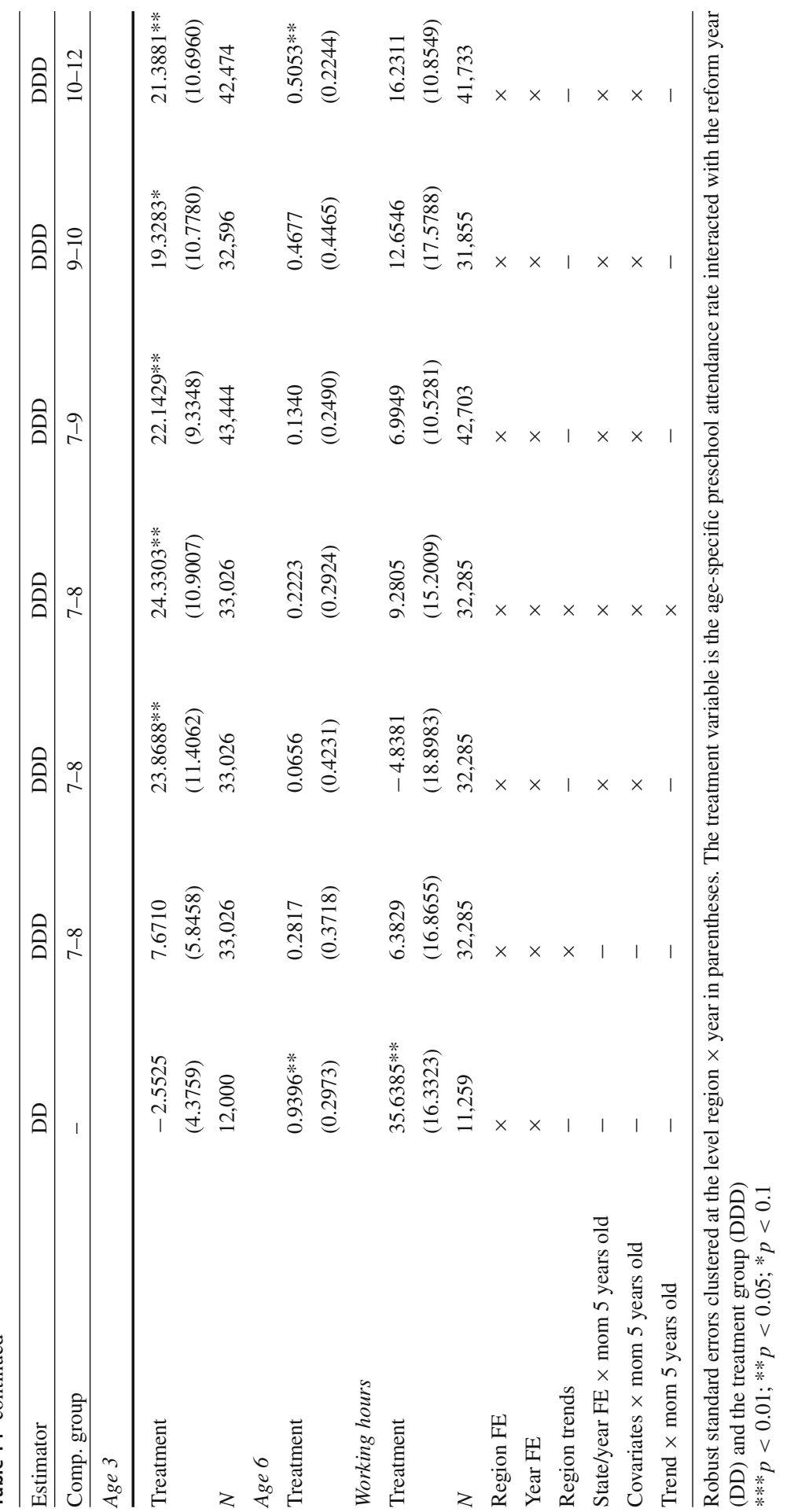




\section{References}

Akgündüz YE, Plantenga J (2018) Child care prices and maternal employment: a meta-analysis. J Econ Surv 32(1):118-133

Angrist JD, Pischke J-S (2008) Mostly harmless econometrics: an empiricist's companion. Princeton University Press, Princeton

Bauernschuster S, Schlotter M (2015) Public child care and mothers' labor supply: evidence from two quasi-experiments. J Public Econ 123:1-16

Berlinski S, Galiani S (2007) The effect of a large expansion of pre-primary school facilities on preschool attendance and maternal employment. Labour Econ 14(3):665-680

Berlinski S, Galiani S, Gertler P (2009) The effect of pre-primary education on primary school performance. J Public Econ 93(1):219-234

Bettendorf LJ, Jongen EL, Muller P (2015) Childcare subsidies and labour supply: evidence from a large Dutch reform. Labour Econ 36:112-123

Blanden J, Del Bono E, McNally S, Rabe B (2016) Universal pre-school education: the case of public funding with private provision. Econ J 126(592):682-723

Blau D, Currie J (2006) Pre-school, day care, and after-school care: who's minding the kids? In: Hanushek E, Welch F (eds) Handbook of the economics of education, vol 2. Elsevier, Amsterdam, pp 1163-1278

Brilli Y, Del Boca D, Pronzato CD (2016) Does child care availability play a role in maternal employment and children's development? Evidence from Italy. Rev Econ Household 14(1):27-51

Cascio EU, Schanzenbach DW (December 2013) The impacts of expanding access to high-quality preschool education. Working Paper 19735, National Bureau of Economic Research

Cascio EU (2009) Maternal labor supply and the introduction of kindergartens into American public schools. J Hum Resources 44(1):140-170

EC (2016) Country report. European Commission, Poland

Fitzpatrick MD (2012) Revising our thinking about the relationship between maternal labor supply and preschool. J Hum Resources 47(3):583-612

García-Morán E, Kuehn Z (2013) With strings attached: grandparent-provided child care and female labour market outcomes. SOEP papers 610/2013

Havnes T, Mogstad M (2011) Money for nothing? Universal child care and maternal employment. J Public Econ 95(11):1455-1465

Heinen J, Wator M (2006) Child care in Poland before, during, and after the transition: still a women's business. Soc Politics 13(2):189-216

Herbst M, Strawiński P (2016) Early effects of an early start: evidence from lowering the school starting age in Poland. J Policy Model 38(2):256-271

Kotowska IE, Michon P, (2008) International review of leave policies and related research 2008. Institute of Education University of London. International Network on Leave Policies and Research, Ch. Poland

Lalive R, Schlosser A, Steinhauer A, Zweimüller J (2013) Parental leave and mothers' careers: the relative importance of job protection and cash benefits. Rev Econ Stud 81(1):219-265

Lovász A (2016) Childcare expansion and mothers' employment in post-socialist countries. IZA World of Labor

Lovász A, Szabó-Morvai Á (2018) Childcare availability and maternal labor supply in a setting of high potential impact. Empir Econ 56(6):2127-2165

Lundin D, Mörk E, Öckert B (2008) How far can reduced childcare prices push female labour supply? Labour Econ 15(4):647-659

Matysiak A, Steinmetz S (2008) Finding their way? female employment patterns in West Germany, East Germany, and Poland. Eur Sociol Rev 24(3):331-345

Michon P (ed) (2010) Work-life balance policy in Czech Republic, Hungary, Poland and Slovakia 19892009, twenty years of transformation. Dom Wydawniczy Harasimowicz, Poznań

Michon P, Kotowska IE (2013) International review of leave policies and related research 2013. Institute of Education University of London, International Network on Leave Policies and Research, Ch. Poland

Morrissey TW (2017) Child care and parent labor force participation: a review of the research literature. Rev Econ Household 15(1):1-24

Mullerova A (2017) Family policy and maternal employment in the Czech transition: a natural experiment. J Popul Econ 30(4):1185-1210

Nollenberger N, Rodríguez-Planas N (2015) Full-time universal childcare in a context of low maternal employment: quasi-experimental evidence from Spain. Labour Econ 36:124-136 
OECD (2008) OECD economic surveys: Poland 2008. Organization for Economic Cooperation and Development, Paris

OECD (2014) Education at a glance: Poland. Organization for Economic Cooperation and Development, Paris

OECD (2015) OECD family database. Organization for Economic Cooperation and Development, Paris

OECD (2017) OECD statistics: LFS indicators. Organization for Economic Cooperation and Development, Paris

Pignatti N (2016) Encouraging women's labor force participation in transition countries. IZA World of Labor

Plomien A (2009) Welfare state, gender, and reconciliation of work and family in Poland: policy developments and practice in a new EU member. Soc Policy Admin 43(2):136-151

Poland Statistics (2019) Poland statistics local data bank. Poland Statistics, Warsaw. https://bdl.stat.gov.pl/ $\mathrm{BDL} /$ dane/podgrup/temat. Accessed 22 July 2019

Puhani P (2000) The Heckman correction for sample selection and its critique. J Econ Surv 14(1):53-68

Rønsen M, Sundström M (1996) Maternal employment in Scandinavia: a comparison of the after-birth employment activity of Norwegian and Swedish women. J Popul Econ 9(3):267-285

Schönberg U, Ludsteck J (2014) Expansions in maternity leave coverage and mothers' labor market outcomes after childbirth. J Labor Econ 32(3):469-505

van Huizen T, Plantenga J (2018) Do children benefit from universal early childhood education and care? A meta-analysis of evidence from natural experiments. Econ Educ Rev 66:206-222

van Huizen T, Dumhs L, Plantenga J (2019) The costs and benefits of investing in universal preschool: evidence from a Spanish reform. Child Dev 90(3):e386-e406

Publisher's Note Springer Nature remains neutral with regard to jurisdictional claims in published maps and institutional affiliations. 